\title{
Amphibian Research and Monitoring Initiative: Concepts and Implementation
}

By Paul Stephen Corn, Michael J. Adams, William A. Battaglin, Alisa L. Gallant, Daniel L. James, Melinda Knutson, Catherine A. Langtimm, and John R. Sauer

Prepared in cooperation with the National Park Service,

U.S. Fish and Wildlife Service, and

Bureau of Land Management

Scientific Investigations Report 2005-5015 


\section{U.S. Department of the Interior \\ Gale A. Norton, Secretary \\ U.S. Geological Survey \\ Charles G. Groat, Director}

U.S. Geological Survey, Reston, Virginia: 2005

For sale by U.S. Geological Survey, Information Services
Box 25286, Denver Federal Center
Denver, CO 80225
For more information about the USGS and its products:
Telephone: 1-888-ASK-USGS
World Wide Web: http://www.usgs.gov/

Any use of trade, product, or firm names in this publication is for descriptive purposes only and does not imply endorsement by the U.S. Government.

Although this report is in the public domain, permission must be secured from the individual copyright owners to reproduce any copyrighted materials contained within this report.

Suggested citation:

Corn, Paul Stephen, Adams, Michael J., Battaglin, William A., Gallant, Alisa L., James, Daniel L., Knutson, Melinda, Langtimm, Catherine A., Sauer, John R., 2005, Amphibian Research and Monitoring Initiative-Concepts and implementation: U.S. Geological Survey Scientific Investigations Report 2005-5015, 23 p. 


\section{Acknowledgments}

Many people have contributed to the development of the Amphibian Research and Monitoring Initiative (ARMI), contributing time and ideas to numerous meetings and discussions. We thank Dennis B. Fenn and Susan D. Haseltine, particularly, for their support and encouragement. Senior U.S. Geological Survey herpetologists Bruce Bury, Gary Fellers, and Ken Dodd were instrumental in promoting the issue of amphibian decline and paving the way for the ARMI. We thank Bob Alverts, Chauncy Anderson, Jim Collins, Ken Dodd, Robin Jung, Carol Meteyer, Brian Todd, Ralph Tramontano, and Susan Walls for comments and review of various versions of this report. 


\section{Executive Summary}

This report provides the basis for discussion and subsequent articulation of a national plan for the Amphibian Research and Monitoring Initiative (ARMI). The authors were members of a task force formed from within the U.S. Geological Survey (USGS) that included scientists with expertise in biology, cartography, hydrology, and statistics. The assignment of the task force was to extend work begun by the National Amphibian Leadership Group. This group, composed of senior USGS scientists, managers, and external authorities, met in Gainesville, Florida, in February 2000'. The product of this meeting was a document outlining the framework for a national program to monitor amphibian populations and to conduct research into the causes of declines.

The ARMI program has the following objectives:

- Establish a network designed to monitor the status and changes in the distributions and abundance of amphibian species and communities in the U.S. and its territories (for example, Puerto Rico and the U.S. Virgin Islands).

- Identify and monitor environmental conditions known to affect amphibians and document their differences across the Nation.

- Conduct research that identifies causes of amphibian population change and malformations.

- Provide information to managers, policymakers, and the public in support of amphibian conservation.

The task force began its deliberations with the pyramid model for research and monitoring outlined in the national framework document. The framework can be conceptualized as a pyramid with extensive and necessarily coarse measurements at many sites across the country (the base of the pyramid), intensive research efforts at a relatively small number of sites throughout the country (the top of the pyramid), and mid-level efforts at a moderate number of sites (the middle of the pyramid). Integration of the three levels would be achieved through research and modeling.

Monitoring will occur at all levels of the pyramid, but emphasis will be at the middle level. This level is characterized by a definable study area (for example, a national park), from which a statistical sample of study sites can be chosen. From these sites and for each species studied, population trends will be tracked by changes in site occupancy. Species richness will be another response variable in systems with high numbers of species. Occupancy incorporates the probability of detection, which allows unbiased estimates of annual occurrence and of trends. Monitoring at the apex of the pyramid consists of intensive population studies at a small group of selected sites designed to determine demographic and life-history characteristics of key species, to relate environmental change to changes in demographic and life-history characteristics over time, and to study causeeffect relationships and(or) evaluate new methods and protocols. Gathering useful data at the base of the pyramid will be more difficult, because this level involves lands that the Department of the Interior (DOI) does not manage. Existing programs that collect data at this scale also have methodological problems and are managed by several different groups.

\footnotetext{
Attendees at this meeting included Bill Battaglin, Viginia Burkett, Norita Chaney, Steve Corn, Ken Dodd, Alisa Gallant, Russ Hall, Sue Haseltine, Dan James, Doug Johnson, Karen Kaye, Cathy Langtimm, Carol Meteyer, Dave Pyke, Tom Stohlgren, and Gary Williams.
} 
Studies of the causes of amphibian declines and deformities will be based on hypotheses generated by monitoring data and by the expert opinion of USGS scientists. Hypotheses also will be generated using a tiered approach of increasing complexity, consisting of (1) an initial assessment and monitoring of potential stressors in ARMI study areas; (2) experimental research to isolate causality between potential stressors and declining occupancy or frequent malformation of individual amphibian species; and (3) modeling to evaluate relations among potential stressors and individual species occupancy and malformation rates, overall species richness, and relative susceptibility of various amphibian species to changes in environmental conditions or potential stressors; and (4) model validation using an iterative process of continued monitoring and experimentation.

Methods development and protocol description are expected to be a continuing process. Existing methods need to be adapted and new methods developed to initiate the program. Continued development is anticipated because of the adaptive nature of the research program. As results accumulate, new research directions are expected to emerge requiring adjustments to existing methods and protocols. To maintain the ARMI at "state of the science" and at the forefront of monitoring technology, appropriate new techniques, analysis, and models will need to be incorporated into the ARMI program as they become available. Because amphibians and amphibian habitats are highly diverse nationally, most protocol development must occur at the regional level. The ARMI, however, will continually strive to coordinate and scale up the regional efforts. For example, the techniques used to monitor occupancy necessarily vary both within and among regions, but the unbiased nature of the estimator allows regional and national comparison, synthesis, and analysis of trends in occupancy.

Two national databases are associated with the ARMI program: a relational database that houses the ARMI field-survey data and the ARMI Atlas for Amphibian Distributions, a county- or subcounty-level compendium of historic and current species presence, documented for all amphibian species known to occur in the U.S. An integrated national database of survey data will benefit ARMI investigators, cooperators, DOI and other Federal land managers, and scientists worldwide with an interest in amphibian status and global conservation issues.

A variety of analyses will be conducted to assess the status and trends of amphibian populations, to determine biotic and abiotic

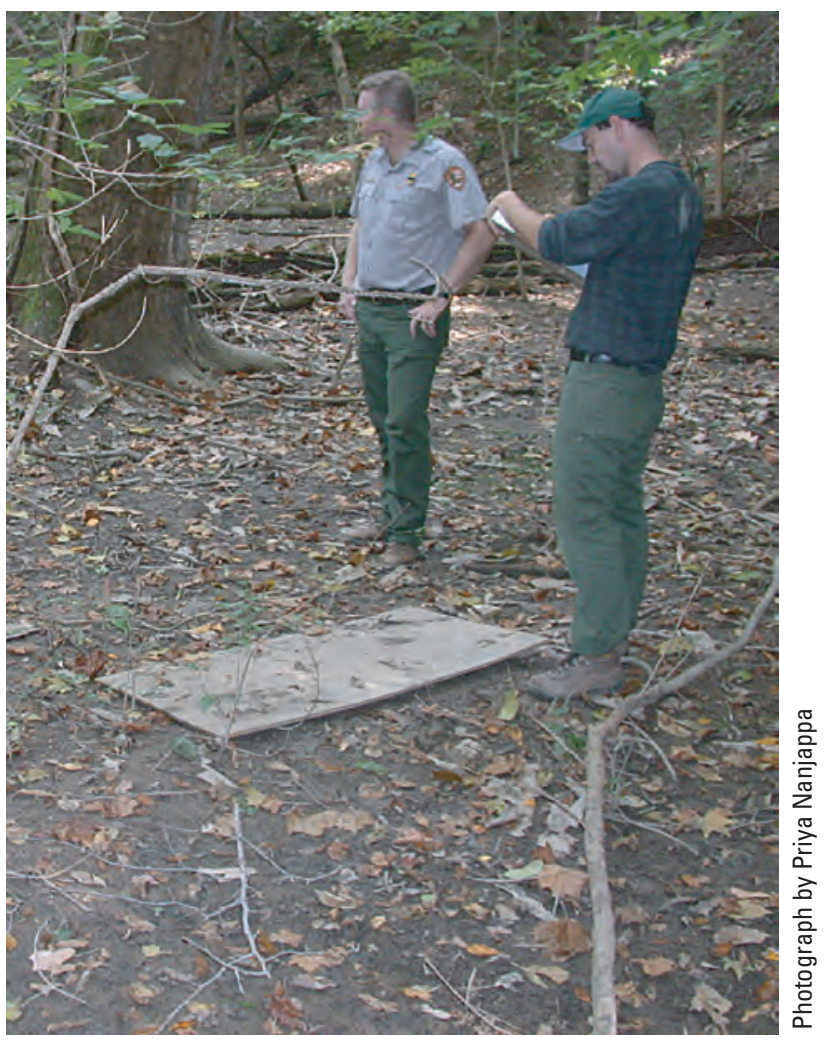


stressors, and to improve understanding of the relations between amphibians and environment. Different mechanisms for reporting these results can be used to provide regional and national syntheses; to provide feedback for determining whether changes in protocols, monitoring strategies, and(or) research activities should be considered (adaptive research and monitoring); and to provide decision-support tools for land managers and policymakers.

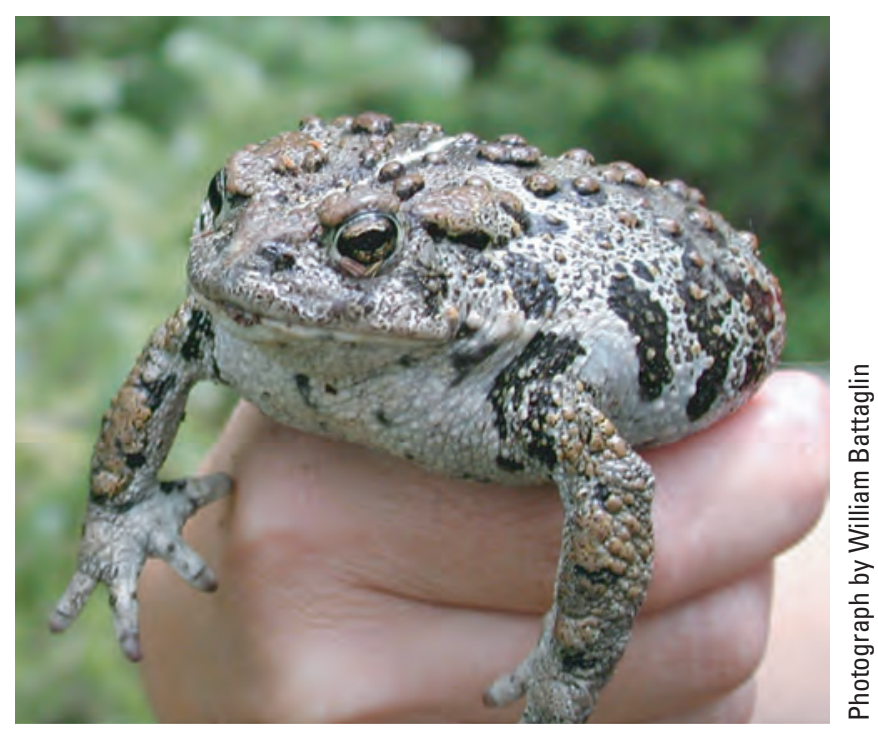

Partnerships are important at every level of the monitoring pyramid. As a first priority, the ARMI is developing strategies for the mid-level of the pyramid and working with DOI landmanagement partners to identify Federal land areas and objectives for USGS monitoring efforts. As the program matures, a major task of the ARMI will be to develop collaborative relationships with agencies, universities, and organizations possessing long-term intensive data and expertise and to integrate this information into regional and national status and trends reports for amphibians. International partnerships can provide an important context for the information collected by the ARMI program and can prove fruitful in the investigation of problems of global concern.

The conceptual designs outlined for each component of the ARMI already are in various stages of implementation and, in some instances, have been in operation for some time. We have an active national program, with research and monitoring proceeding across the U.S. and at all three levels of the pyramid. Integration, however, will be key to realizing a larger and greater value above the excellent value already coming out of the ARMI's functioning parts. Integration needs to proceed in multiple directions - across regions, across disciplines, and across the three levels of research and monitoring within the pyramid. Coordinating the component parts into a well-integrated national program will require the full-time efforts of more than one individual. As partners come into the program and data accumulate for processing, analysis, and reporting, the integration of the program will become even more complex. It is critical to anticipate the needs of the ARMI for the near and distant future and to begin to establish now an infrastructure for national coordination and integration. 


\section{Contents}

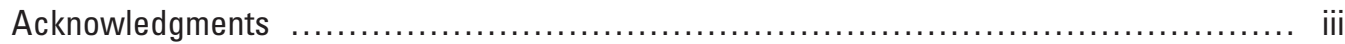

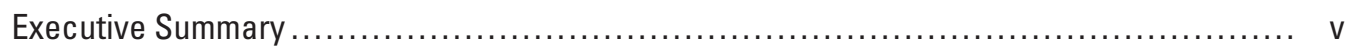

History, Objectives, and Organization of the Amphibian Research and

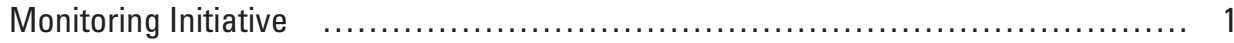

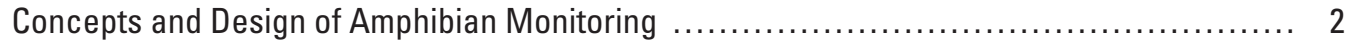

A Hierarchical Framework ...................................................... 2

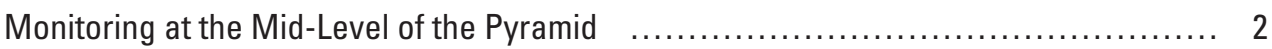

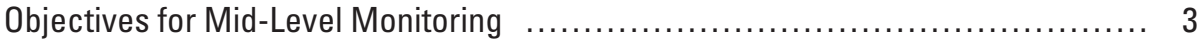

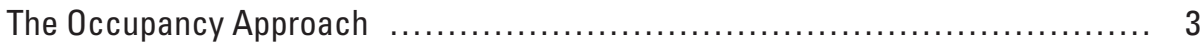

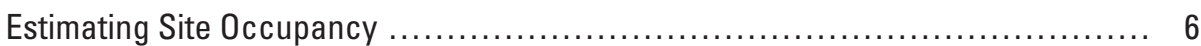

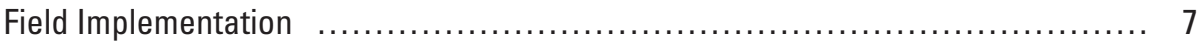

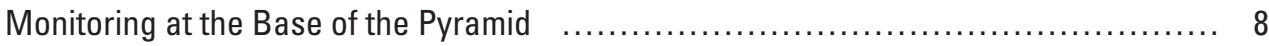

The Amphibian Research and Monitoring Initiative National

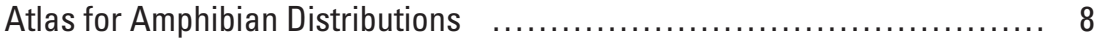

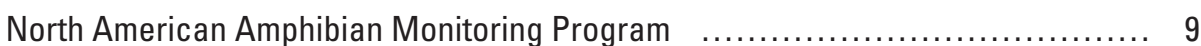

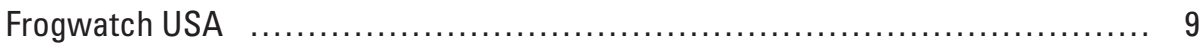

North American Reporting Center for Amphibian Malformations $\quad$................. 10

Implementation of Base-Level Monitoring ................................. 10

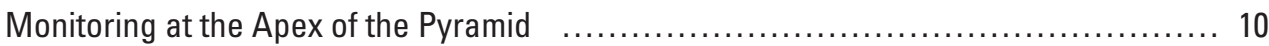

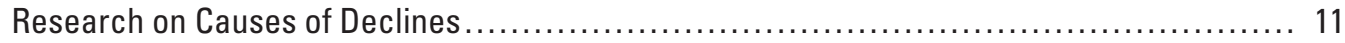

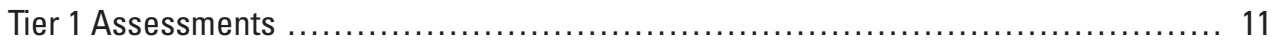

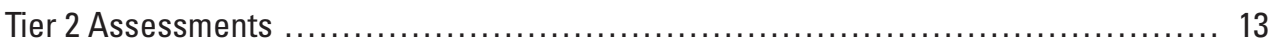

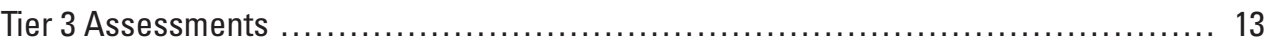

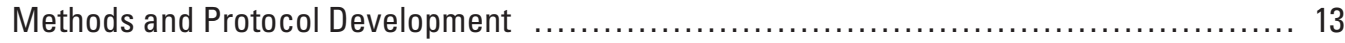

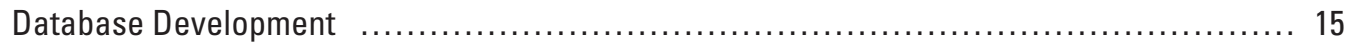

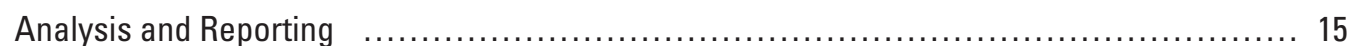

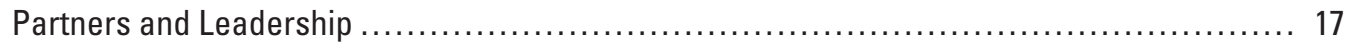

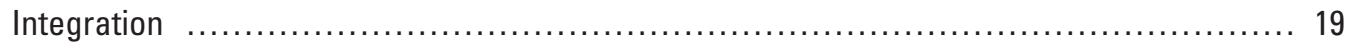

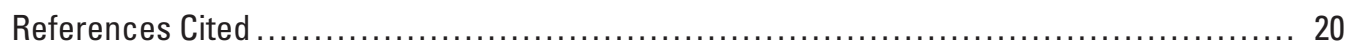

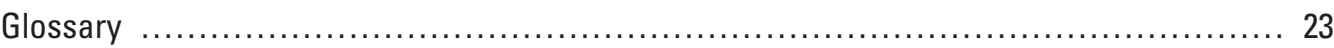

\section{Figures}

1. Map showing regional organization of the Amphibian Research and

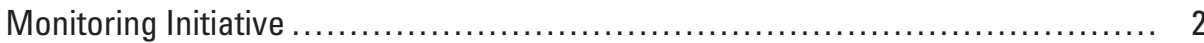

2. The pyramid conceptual model applied to the Amphibian Research and Monitoring Inititative

3. Species distribution map for $A$, Wood frog (rana sylvatica); $B$, American bullfrog (rana catesbeiana); $C$, Eastern newt (notophthalmus viridescens); and $D$, Tiger salamander (ambystoma tigrinum) 


\title{
Amphibian Research and Monitoring Initiative: Concepts and Implementation
}

\author{
By Paul Stephen Corn, Michael J. Adams, William A. Battaglin, Alisa L. Gallant, Daniel L. James,
} Melinda Knutson, Catherine Lagtimm, and John R. Sauer

\section{History, Objectives, and Organization of the Amphibian Research and Monitoring Initiative}

Amphibian decline has been recognized as a global issue since the meeting of the First World Congress of Herpetology in England in 1989. The rapidly growing literature on the status of amphibians and the causes of declines has been the subject of several reviews, including Collins and Storfer (2003), Linder and others (2003), and Semlitsch (2003). Two recent analyses suggest that the problem of amphibian declines may be accelerating (Stuart and others, 2004; Thomas and others, 2004). The increasing interest and demand for information to better understand the status and the underlying causes for declines and malformations prompted the U.S. Congress to fund the Amphibian Research and Monitoring Initiative (ARMI) in 2000. ARMI is a national program coordinated by the U.S. Geological Survey (USGS), the science and research bureau for the Department of the Interior (DOI). The goals of the program are to implement a plan to monitor trends in amphibian populations on DOI lands and to study the causes for declines, should they be detected. This program includes cooperation with the National Park Service (NPS), the U.S. Fish and Wildlife Service

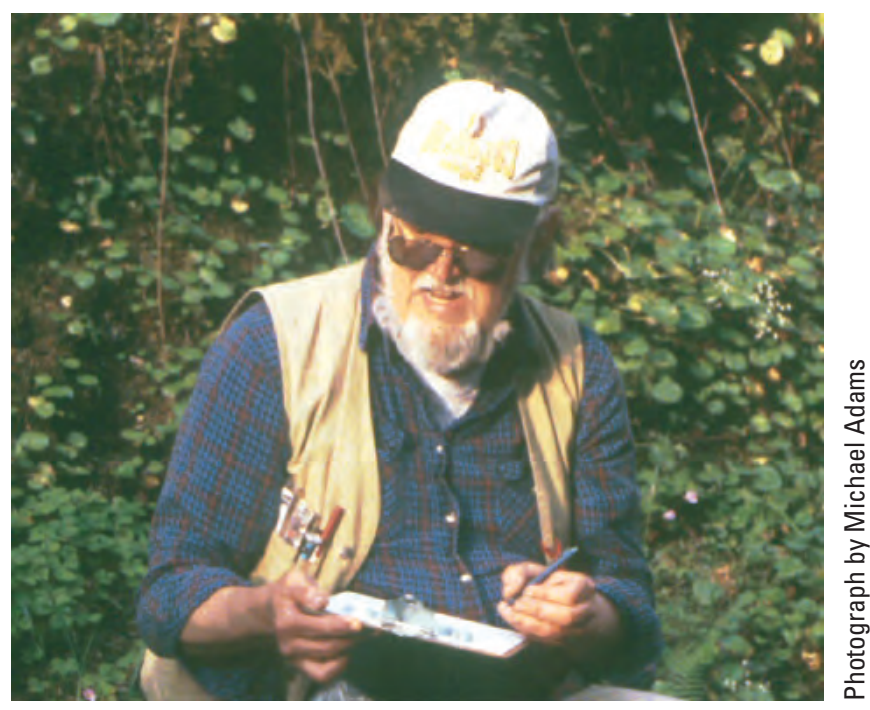

(USFWS), and the Bureau of Land Management (BLM). The USGS is uniquely qualified to develop and provide scientific leadership for such an effort. It has a long record of studies on amphibian life history, sampling techniques, toxicology, and health-related issues, and it has the responsibility for many natural-resources monitoring programs at regional, national, and continental scales.

The goal of ARMI is to better understand the dynamics of amphibian population trends, including causes of declines, so that DOI agencies and other land managers have the most accurate information from which to develop effective ways to manage and conserve amphibian populations. Specific objectives include:

- Establish a network designed to monitor the status and changes in the distributions and abundance of amphibian species and communities in the U.S.

- Identify environmental conditions known to affect amphibians and document their differences across the Nation.

- Conduct research that identifies causes of amphibian population change and malformations.

- Provide information to managers, policymakers, and the general public in support of amphibian conservation.

To take advantage of regional knowledge and expertise, the U.S. has been divided into seven blocks of States that are the focus of regional herpetological investigations (fig. 1). The monitoring program is coordinated in each region by USGS herpetologists who collaborate with USGS hydrologists. ARMI-sponsored research is conducted by USGS scientists nationally. Data are managed jointly by the Patuxent Wildlife Research Center and the Western Ecological Research Center. A Web site, Geographical Information Systems (GIS) resources, an interactive Web-based mapping tool, and other remote-sensing resources are overseen by the National Center for Earth Resources Observation and Science (EROS) Data Center. Oversight is provided by a steering committee, with members from within the USGS and from a number of major government environmental agencies and nongovernment organizations. 


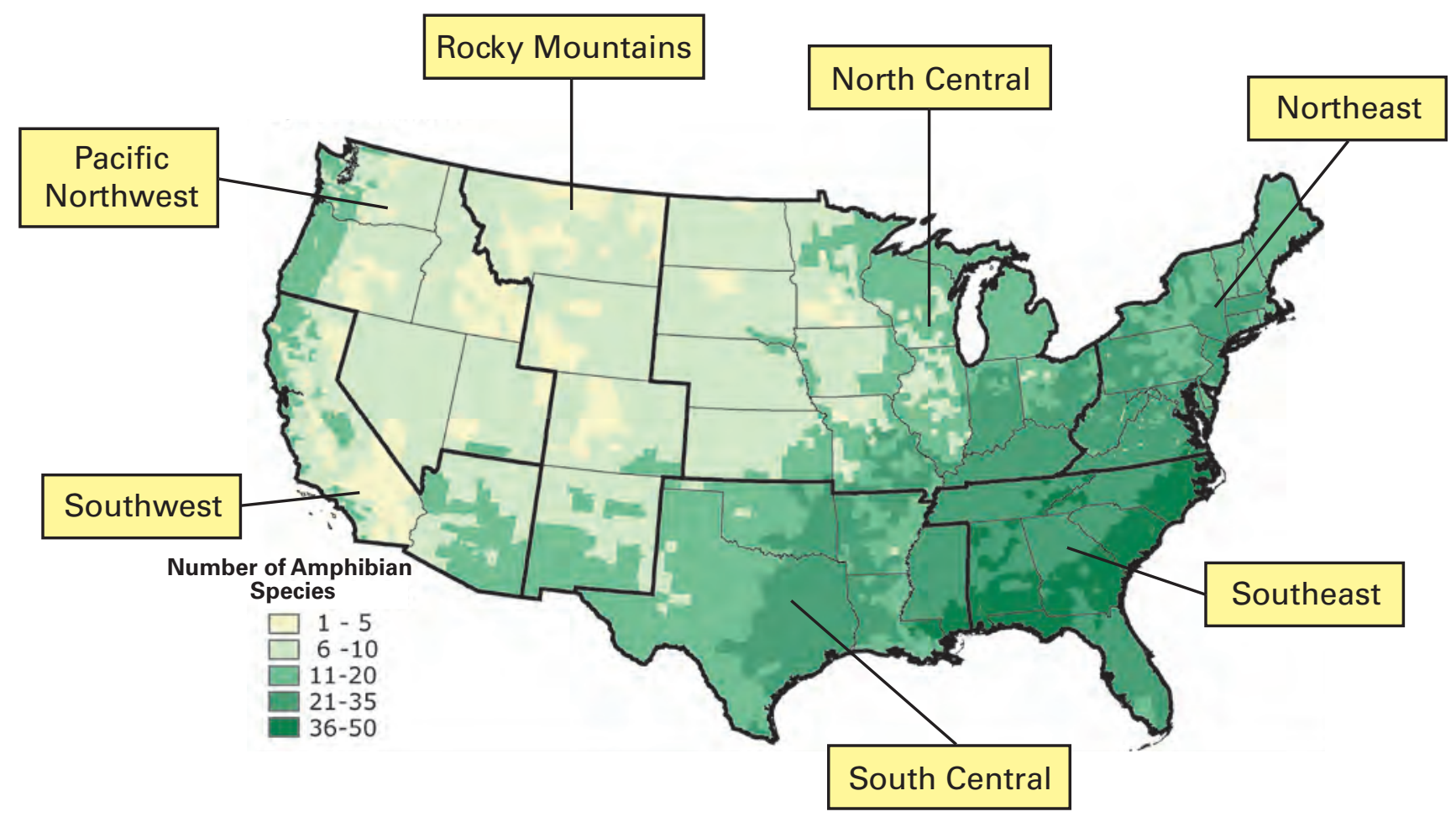

Figure 1. Regional organization of the Amphibian Research and Monitoring Initiative. Puerto Rico and the U.S. Virgin Islands are in the Southeast Region, Alaska is in the Pacific Northwest Region, and Hawaii is in the Southwest Region. Amphibian species richness based on data in the Amphibian Research and Monitoring Initiative National Atlas for Amphibian Distributions.

\section{Concepts and Design of Amphibian Monitoring}

\section{A Hierarchical Framework}

One of the greatest challenges to developing this national monitoring plan is the highly regional nature of amphibians in North America. With the exception of the woodfrog (Rana sylvatica), which ranges from Georgia to Alaska but does not occur in most of the West, and the bullfrog (R. catesbeiana), which is nonindigenous west of the Great Plains (Bury and Whelan, 1984), there are no species of U.S. amphibians with truly continental distributions. Amphibians occupy diverse habitats that require specialized sampling techniques. No single technique is capable of sampling amphibians across the country, and the factors affecting amphibians differ among regions. This diversity argues for a highly regionalized approach to amphibian monitoring and research; however, it also is important to integrate these regional programs in a way that allows for a national synthesis and for analysis at a wide range of spatial scales.

A design modified from the Committee on Environment and Natural Resources (CENR) report "Integrating the Nation's Environmental Monitoring and Research Networks and Programs-A Proposed Framework" (CENR, 1997) is the model used by the USGS to offer leadership in amphibian monitoring and research and to achieve regional and national assessments of status and trends. The framework describes a pyramid (fig. 2). At the base, extensive but necessarily coarse measurements are made at many sites across the country. At the apex of the pyramid, intensive research and population monitoring is conducted at a relatively small number of sites throughout the country. At the mid-level of the pyramid, monitoring directed toward detecting change in occurrence and abundance of species across the landscape is conducted at a moderate number of sites.

\section{Monitoring at the Mid-Level of the Pyramid}

This is the level of monitoring where ARMI and its partners will come together in a national monitoring effort. USGS monitoring on protected DOI lands, as mandated by U.S. Congress, will provide the core framework, while Federal, State, and private partners collaborating with the USGS extend the effort to non-DOI land units to make it a truly national program. By necessity, the design and implementation of this framework is modular. Land areas currently being monitored by USGS investigators were chosen by subjective criteria such as previous monitoring efforts or perceived importance of the habitat. New areas will be incorporated as managers or stewards of selected areas willingly enter the program. Because new monitoring areas will not be randomly chosen from available areas, statistical inference will be focused on each land 
unit and will provide substantial information to managers and stewards of the selected areas. Statistical inference at a regional and national level will be limited, although monitoring in these areas can and will inform at broader landscape levels.

\section{Objectives for Mid-Level Monitoring}

- Provide geographic and temporal information on change at the scale of the individual park, refuge, or other land unit (mid-level monitoring area).

- Provide estimates of change within strata of management interest within the park, refuge, or land unit.

- Provide information for modeling amphibian and environment-stressor associations at the mid-level monitoring area and for mapping these associations at the regional level.

\section{The Occupancy Approach}

Amphibian monitoring on Federal lands will emphasize estimation of well-defined parameters using statistical procedures that can be applied to a variety of species in different regions. All sampling will be based on a defined sample frame with a specified target population and will incorporate a method of estimating the detection probability of each species sampled (Box A). Because estimating abundance of wildlife populations, including amphibians, can be difficult and expensive, use of raw counts or other indices such as relative abundance is sometimes suggested (Caughley and Sinclair, 1994; Alford and Richards, 1999; Engeman, 2003). Although Smith and Petranka (2000) found that counts of terrestrial salamanders were highly predictive of population sizes estimated from capture-recapture data, indices usually rely on assumptions about detection probabilities that are difficult to

\section{APEX MONITORING}

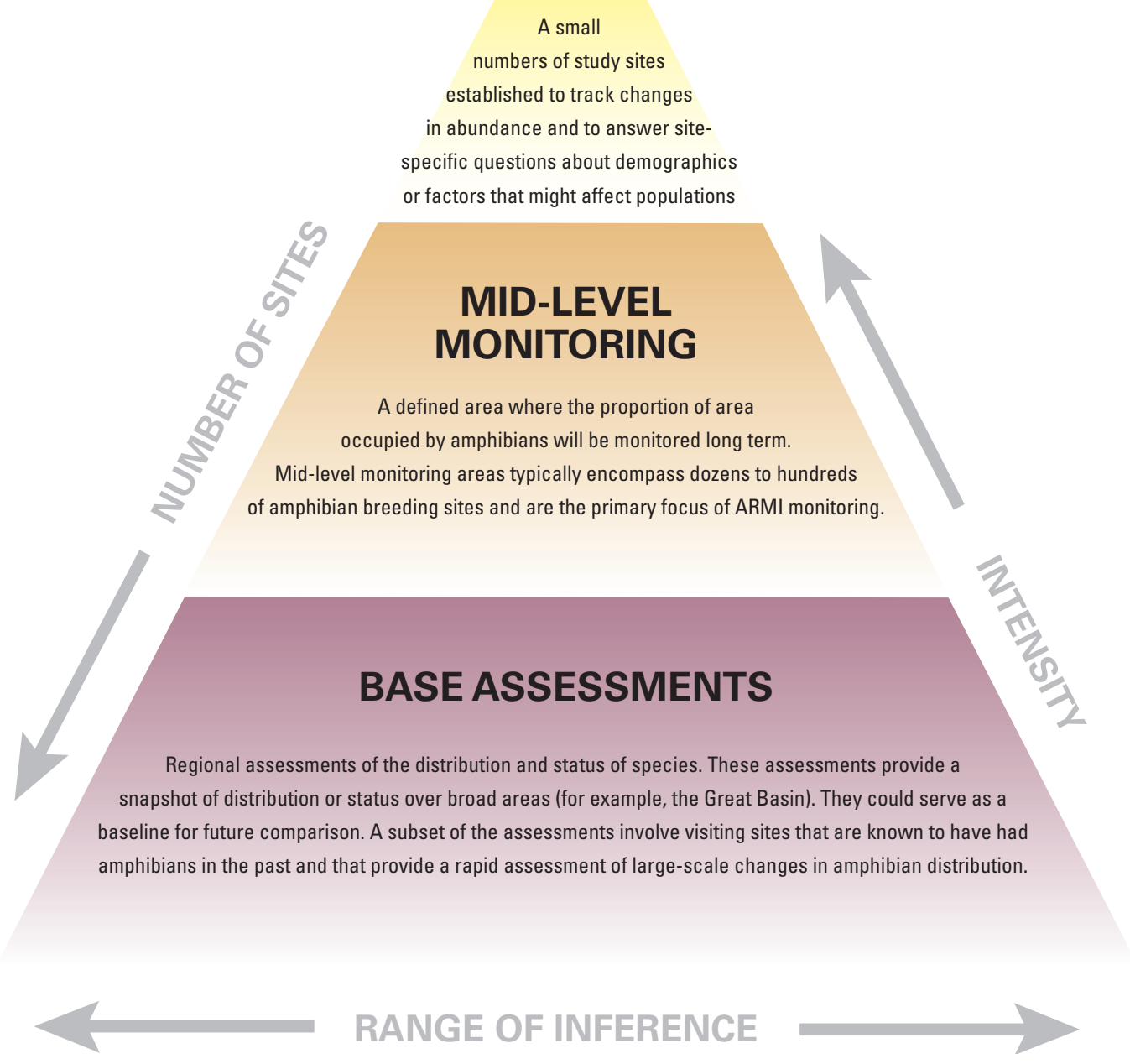

Figure 2. The pyramid conceptual model applied to the Amphibian Research and Monitoring Initiative. 


\section{Key Elements of ARMI Regional Monitoring at Each Level of the Pyramid}

Mid-Level of the Pyramid.- It may seem strange to start in the middle, but this will be the core of ARMI. Most integration will occur at the scale of individual mid-level monitoring areas. Each ARMI region will establish two to three mid-level monitoring areas using the following guidelines:

- A defined sample frame is essential. This implies that the investigator maps the boundary or boundaries of the mid-level monitoring area, divides it into sampling units, and chooses which units to sample via a probabilistic scheme.

- Occupancy is the primary response variable. This estimator, which incorporates detection probability, will be employed whenever possible. This requires multiple visits within a season to at least a subset of sites in each mid-level monitoring area. Regional coordinators will produce annual estimates of occupancy and its variance for a subset of species of their choosing for each mid-level monitoring area each year.

- Disease screening is integral to data collection. Data will be collected at each mid-level monitoring area according to procedures developed by the USGS National Wildlife Health Center.

- Water data are necessary. Regional coordinators will work with a hydrologist to identify and monitor basic water parameters at a subset of mid-level monitoring sites.

- Mid-level data will be used to guide research and monitoring of stressors related to amphibian decline. Regional coordinators, with input from ARMI specialists in hydrology, geography, chemistry, and biology, will identify potential stressors and determine if additional data related to those stressors can and should be collected.

- Partnerships are strongly encouraged. Mid-level monitoring areas need to be established in partnership with client agencies. The NPS, in particular, should be a primary partner because they also are establishing longterm monitoring. Monitoring areas funded solely by the USGS should be located strategically to address specific questions related to amphibian decline, or to increase coverage of poorly represented habitats.

Apex of the Pyramid.-Apex monitoring consists of intensive population monitoring and research at handpicked sites. Apex monitoring does not provide broad inference. Apex monitoring often will consist of egg counts, population estimates, demographic studies, or other detailed population-scale work. Each region will identify one to three apex monitoring sites.

Base of the Pyramid.-Funding constraints and the logistics of emphasizing DOI lands prevent ARMI regions from working effectively at this level. Partnerships with other broad-scale efforts such as the North American Amphibian Monitoring Program (NAAMP) or Frogwatch USA will be encouraged.

- Regional coordinators are encouraged to seek matching funds to conduct broad-scale inventories that incorporate historic site revisits when feasible and when deemed that such information is needed. This is a good way to obtain quick information about amphibian status at a broad scale and to provide the information most sought after by many of our partners. Depending on regional priorities and resources, regional coordinators also may fund basic research on causes of amphibian decline that have broad regional or national relevance.

satisfy. Therefore, indices are very likely to result in biased estimates of abundance and change in abundance (Anderson, 2001, 2003; MacKenzie and Kendall, 2002; Schmidt, 2003; Storfer, 2003). Instead, ARMI will apply statistical methods that use species presence-absence data from a sample of sites to estimate the proportion of sites occupied by each species and species richness. In collecting and analyzing presenceabsence data, it is recognized that "absence" pertains to two possible conditions: (1) The species is truly absent from the site, or (2) the species is present but undetected. By estimating detection probabilities, the naïve estimate of occupancy is adjusted to provide an unbiased estimate of the proportion of sites truly occupied, allowing comparisons among studies with differing methods or level of effort (Bailey and others, 2004). The methods and conceptual designs of ARMI were developed through discussions held at several organizational meetings and through the deliberations of ARMI herpetologists, hydrologists, geographers, and biometricians representing three disciplines within the USGS.

Why an approach based on presence-absence data?Amphibians pose a number of difficulties when designing surveys to determine long-term trends. An ideal survey would 
include unbiased estimates of population size at every location studied. Unfortunately, population estimates of most amphibians are difficult and expensive to obtain, limiting their feasibility. Many amphibian surveys employ indices as surrogates to population estimates, but a useful index must provide unbiased estimates of changes in abundance. To provide such unbiased estimates of population change, the numbers of adults, tadpoles, or egg masses recorded must reflect a constant proportion of the true population size among study sites and among years at the same study site; however, satisfying this condition is likely to be difficult for most studies.

Another complication is that amphibians tend to have highly variable populations. This inherent variability means that even if adequate population estimates or reliable indices were available, the power to detect changes will be low and long-term data will be required. The problem may be exacerbated by the pattern of annual variation. Alford and Richards (1999) observed that population dynamics of pond-breeding amphibians are based on variation in recruitment from the larval stage, which is much greater than variation in adult survival. This results in populations that have the potential for rapid changes in abundance. Populations that are more or less stable over the long term may exhibit large increases in abundance that are balanced by more frequent, small decreases. This could explain the observations from several long-term studies of amphibian abundance that recorded declines, sometimes lasting for several years, followed by increases in abundance back to or greater than the population size before the decline began (Pechmann and others, 1991; Semlitsch and others, 1996; Meyer and others, 1998). For several groups (ranid frogs, toads, ambystomatid salamanders), Alford and Richards (1999) found that it was significantly more likely to observe a decline in population size than an increase in any one year.

Green (2003) analyzed a variety of amphibian population time series and also found declines to be more frequent than increases, but the magnitude of declines and increases did not differ. This does not support the scenario proposed by Alford and Richards (1999), but it does support the analyses by Houlahan and others (2000) that shows a global trend of declining population size since the 1950s. Alford and others (2001), however, pointed out that the data used for these analyses are not randomly distributed geographically, and that the data were collected for a variety of purposes other than detecting trends in population size. Furthermore, some of these data are simple counts of individuals or egg masses. Without detection probabilities, these data are inadequate to assess trends, because the changes observed could be due to changes in detection instead of changes in abundance (MacKenzie and Kendall, 2002).

Habitat availability and attractiveness of water bodies as breeding sites change over time, which may compromise use of single sites for monitoring long-term trends (Alford and Richards, 1999; Skelly and others, 1999). Furthermore, the precision of population estimates (hence, the power for detecting change) depends on sampling intensity, with single visits (index data) providing the least useful information for detecting changes.

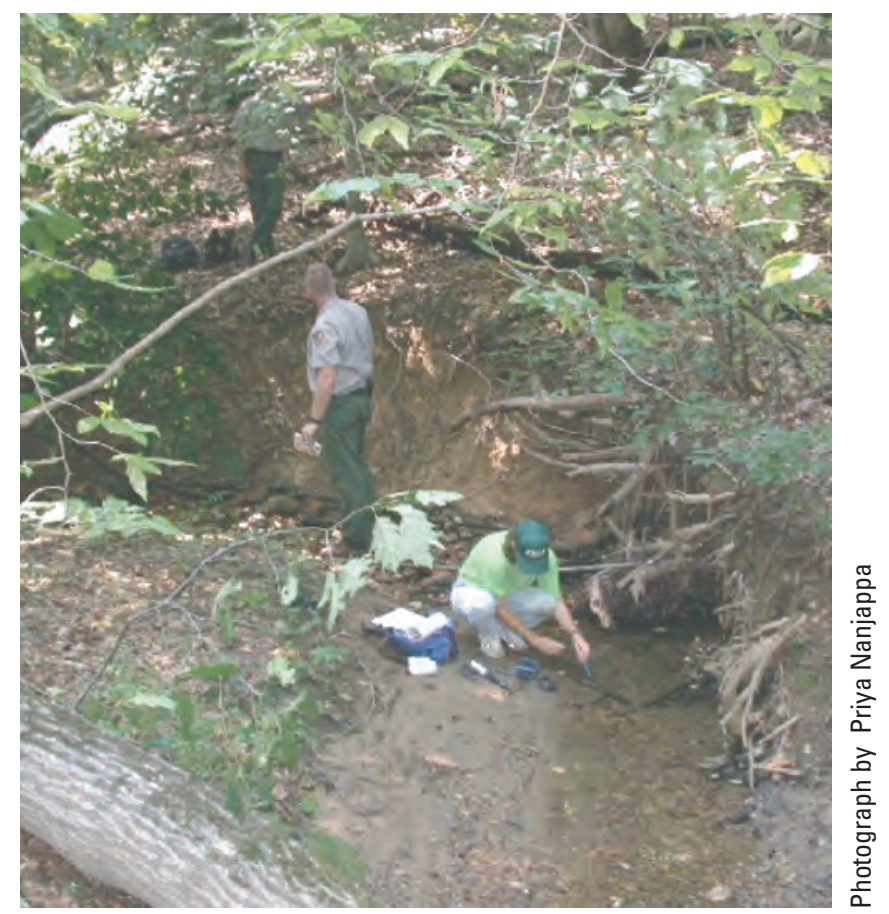

The inadequacy of existing data on amphibian populations suggests that a new approach is necessary. Green (1997) provided a useful framework for amphibian populations that deals with sampling problems and low power for detecting changes. Green distinguished between declines in size of populations and declines in numbers of populations:

A decline is the condition whereby the local loss of populations across the normal range of a species so exceeds the rate at which populations may be established, or reestablished, that there is a definite downward trend in population number.

The approach of monitoring changes in site occupancy of species based on presence-absence data allows for the estimation of several parameters that can be used to study population and community dynamics, estimate extinction and colonization probabilities, and test hypotheses concerning environmental factors affecting those dynamics. Research in wildlife estimation theory seeks to incorporate measures of detection probability in the estimation procedures and reduce unknown bias due to some species invariably being missed or overlooked during surveys. In one class of estimators, species richness is the state variable of interest (Boulinier and others, 1998, 2001; Nichols and others, 1998a, b; Cam and others, 2000). In the other class of estimators, the proportion of patches or area occupied is the state variable of interest (Erwin and others, 1998; MacKenzie and others, 2002). Thus far, these new estimators have been applied primarily to data from bird surveys, but they hold considerable promise for amphibian surveys (MacKenzie and others, 2002, 2003).

In addition to the strength of this approach for biological and statistical reasons, there are considerable logistical benefits. Presence-absence data are more reliably and easily 
collected than data necessary for estimates of population size and do not require marking animals. The methods do not require technically sophisticated field surveys, and protocols are potentially transferable to persons who are not specialists in amphibian biology, although technical proficiency and experience in amphibian field techniques and species identification are imperative.

Obviously, no single approach can cover all species or all objectives in a national monitoring program. Other approaches will be developed as needed, but this approach offers the best possibility for immediate and successful implementation, with subsequent data analysis providing reliable indication of the status of selected amphibian species.

\section{Estimating Site Occupancy}

Estimating occupancy yields species-specific statistical inferences with regard to the proportion of discrete sample sites (for example, ponds, caves, wetlands, stream reaches, terrestrial quadrats) that are occupied by a species. Pond-based surveys and inferences already are accepted in the amphibian literature (Kareiva and others, 1997; Skelly and others, 1999; Joly and others, 2001; Marsh and Trenham, 2001), and the conceptual transition to terrestrial sample plots is easily made. As populations increase in abundance they should expand into available habitat with a concomitant increase in occupancy. As populations decrease in size, distributions should shrink, with fewer species in the sampling units and a concomitant decline in occupancy. Thus, the occupancy estimator can provide indirect information on temporal and spatial variations in species abundance. With simultaneous monitoring at sampling sites of environmental variables and stressors that can affect amphibians, correlation with possible causes of change can be established and studied. For ARMI, surveys based on occupancy are attractive because of the ease of implementation and the potential for general application to all regions and amphibian habitats. Field methods can be tailored for different kinds and configurations of habitats, landscapes, and amphibian communities.

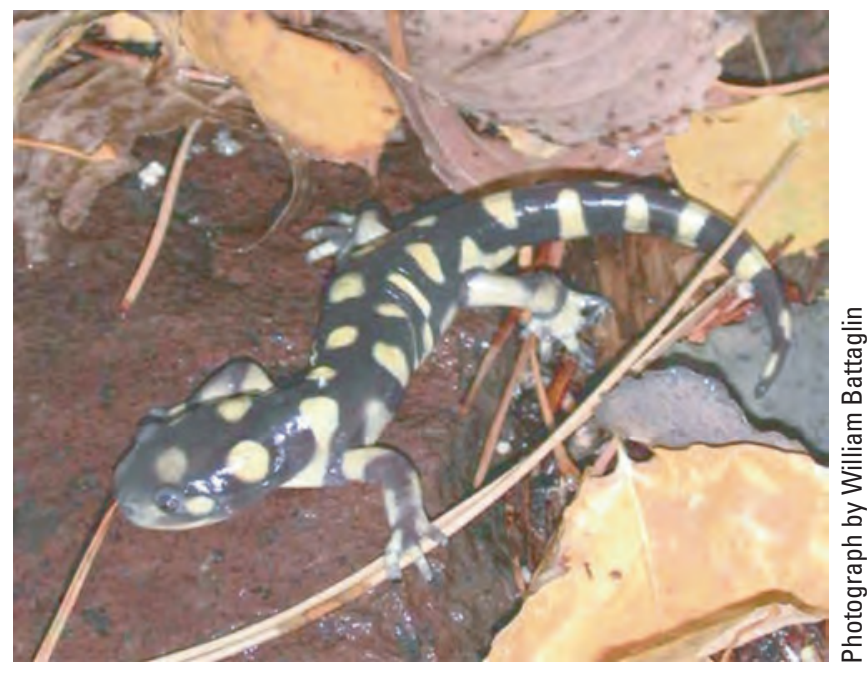

The occupancy approach also can be used to address issues of metapopulation dynamics, which may be important to many amphibian species (Alford and Richards, 1999). Metapopulations are networks of subpopulations that occupy discrete habitat patches but are united by migration (Hanski and Gilpin, 1996). Metapopulation theory is particularly applicable to pond-breeding amphibians (but has not been demonstrated to apply to terrestrial salamanders). Research on salamanders and anurans generally supports the existence of semi-isolated subpopulations centered around breeding ponds and linked by migration (Gill, 1978; Berven and Grudzien, 1990; Sinsch, 1992; Sinsch and Seidel, 1995). In amphibian metapopulations, migration among nearby ponds is relatively frequent, but more isolated sites have less contact with other populations, have decreased rates of occupancy, and have increasing probability of extinction (Sjögren, 1991; Sjögren Gulve, 1994; Vos and Stumpel, 1996). A focus on metapopulation systems could increase the efficiency of fieldwork (by sampling randomly selected groups of sites instead of random individual sites spread over large, inaccessible landscapes). Not all groups of amphibian populations in a landscape may function as metapopulations, and changes in the surrounding terrestrial environment may have significant influence on extinction rates (Joly and others, 2001; Marsh and Trenham, 2001). The assessment of trend from occupancy data, however, does not depend on metapopulation dynamics.

Using the occupancy approach, models of system dynamics will be parameterized by local extinction and colonization rates. Long-term data (10 years or more) will provide more reliable estimates, but only 2 years of data are required to begin the analysis of system dynamics. Declines will be manifested by local extinctions that exceed colonizations. Patterns of habitat occupancy will allow for some inferences with only a single year of data by testing the hypothesis that occupancy is related to isolation (for example, high rates of vacancy in groups of nearby ponds may indicate a decline). Sampling clusters of sites also will allow for more efficient sampling and analysis of environmental factors that may be related to declines.

A statistical framework and associated software for estimating occupancy and rates of local extinction and colonization have been developed in collaboration with researchers at the USGS Patuxent Wildlife Research Center (MacKenzie and Kendall, 2002; MacKenzie and others, 2002, 2003). This framework allows for modeling with covariates to test hypotheses about environmental effects on the presence or detection probability of species within the sampling unit of interest (for example, ambient temperature effects on the mean estimate of detection probability, presence of fish or bullfrogs, hydrology pattern, fertilizers, proximity to a source population on the presence of species). Note that some index methods do not permit the separation of environmental covariate effects on detection probability and animal presence, precluding reasonable interpretation of results (Schmidt, 2003). Variations in occupancy estimates are expected. The challenge is to isolate variation in occupancy due to natural stressors 
(rainfall patterns, temperature patterns, good or bad year for prey populations) from variation that may result from anthropogenic causes (pollution, habitat loss, parasite infestations, management actions), keeping in mind the complication that humans have changed the weather (land use affects temperature and precipitation). Covariate analysis can help determine where population dynamics fall within expected patterns of variation explained by known factors of change and where variation does not follow explainable patterns (Box B). This is an essential step in testing hypotheses to explain amphibian declines, but it is a step that few entities have the capability to address at a broad scale. With adequate time series, extinction and recolonization probabilities at sampling sites within a sample frame with a defined area of inference can be estimated for species.

\section{Field Implementation}

Each mid-level monitoring area will present unique sampling challenges for implementing occupancy estimation. ARMI is addressing this challenge through annual meetings and workshops that provide opportunities for the regional coordinators, biometricians, and others to meet and resolve their unique challenges. The basic components of implementation are as follows:

1. Define a sample frame with a known range of inference.Investigators routinely cannot apply survey or monitoring techniques over the entire sample frame. In such situations, a subset of sample units is chosen from which to pick sample sites and make statistical inferences. All sites in that sample unit need to have an equal chance of selection for sampling. If sites are selected arbitrarily, the monitoring results only reflect what is happening at those sites and cannot be extrapolated to the rest of the sample frame.

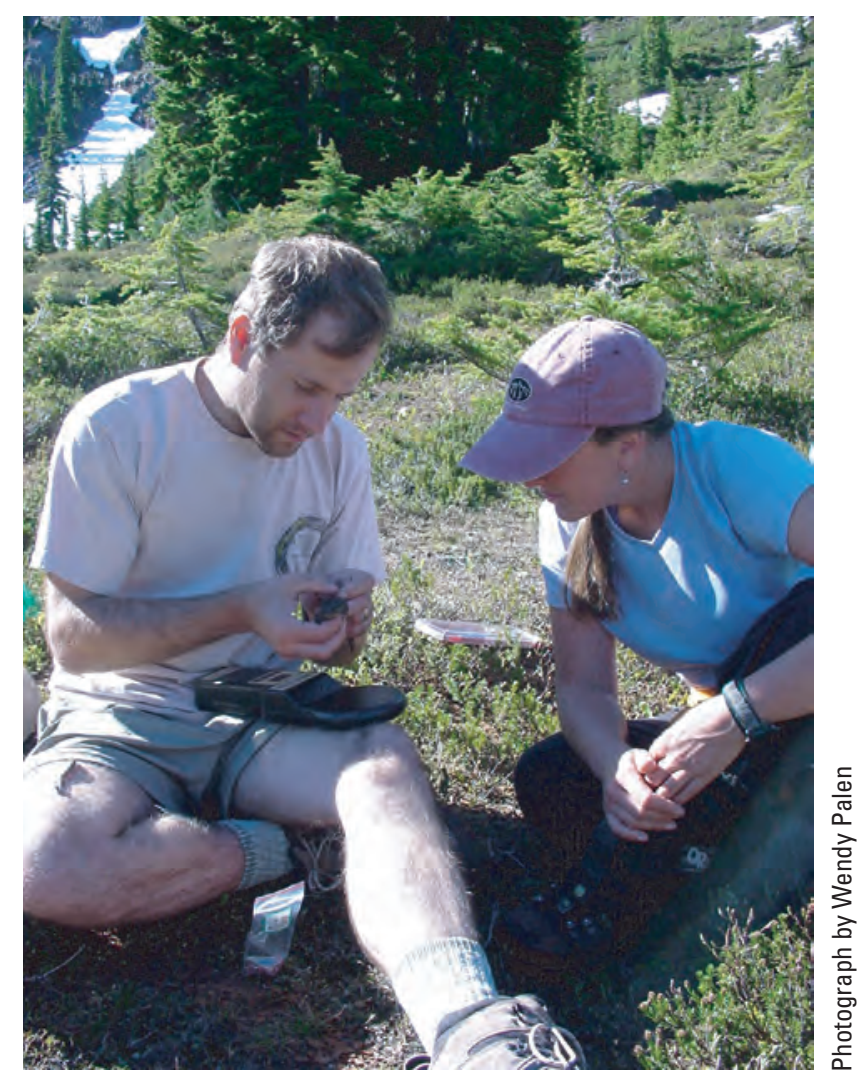

Sample frames will be tailored to the species and landscape of interest. Sample frames need not be one contiguous unit and, for example, may be a network of USFWS refuges on the lower Mississippi River. Conversely, it may be appropriate to have more than one sample frame within a park or refuge. For example, at Okefenokee National Wildlife Refuge in Georgia, there are six different wetland types that harbor different species and amphibian assemblages.

Example 1.-As a species goes from high to low abundance, which sample units lose the species first? Which sample units consistently maintain the species? Which sample units are reoccupied first? Why? Is the pattern of loss or gain consistent each time occupancy increases or decreases? Are these patterns consistent for the same species across different mid-level monitoring areas? If there is a change from a consistent pattern does that mean that there is a problem? Are differences among populations on DOI and non-DOI lands in the same area a cause for concern? Is a consistent declining trend in occupancy by a species indicative of a problem?

Example 2.-As abundance varies, which species within a different mid-level monitoring area show the same patterns of change in occupancy? Which species differ? Are those patterns consistent among different midlevel monitoring areas within an ARMI region? Is one species more vulnerable than another, and why might that be? Are populations that inhabit one habitat type more vulnerable than those inhabiting another?

Example 3.-Within a given species range in the U.S., are there patterns in occupancy that can be identified with geographic gradients such as latitude, elevation, climate variables, known stressors, or periphery versus core of its geographic range? 
2. Apply appropriate field survey techniques.-Appropriate and feasible methods for detecting all targeted species in a sample frame will be consistently applied in all sample units. Multiple survey techniques will be applied to increase the probability of detection (for example, visual survey, auditory surveys, PVC pipes, cover boards). If field techniques, such as calling surveys, are employed that are not capable of detecting certain species in the area (noncalling anurans), then those species cannot be considered as targets for sampling and estimation. Each investigator will decide which species to target.

An important component of survey techniques is the timing of surveys. Surveys must be designed to maximize detectability of the species studied, and this is generally specific to individual study areas or regions. Appropriate timing may vary from year to year because of variable weather conditions.

3. Perform repeat surveys of sampling sites.-Repeat visits during a field season are used to estimate detection probability. Detection probability refers to the near-universal situation in animal population monitoring in which survey methods do not detect all populations present in a study area. The occupancy estimator is designed to incorporate data from repeat site visits so that estimated changes in occupancy reflect true changes in occupancy and not simply changes in detection probability.

4. Estimate Species Richness.-Species richness (fig. 1) provides community-level parameter estimates that can be used to monitor spatial and temporal changes in targeted communities. Estimating variation in species richness through time and among sample units is one means of tracking the status of amphibians as a group and adds another level of information. Furthermore, detection of a change in species richness can alert biologists and managers to potential problems that may require more focused study.

Statistical methods recently have been developed that account for variation in detection probabilities that estimate species richness, standard error, and confidence intervals (Nichols and Conroy, 1996). The data collected and the sampling schemes employed are similar to those used to estimate occupancy, and the same data set often can be used to estimate both species richness and occupancy. Development in this area of estimation research has been intense, and the initial approach and method have been extended to estimate several vital rates in community dynamics important to identifying amphibian declines - rate of increase in species richness, local extinction rates, local species turnover, annual extinction and recolonization probabilities, and probability of species cooccurrence (Nichols and others, 1998a; Hines and others, 1999). Additional methods have been developed to test hypotheses concerning environmental factors affecting temporal (Boulinier and others, 1998) and spatial variation (Nichols and others, 1998b) in species richness, which will be important to identify cause-effect relationships. Methods development was based principally on data supplied by the USGS Breeding Bird Survey (BBS), but the statistical techniques hold promise for amphibians. Application, however, may be limited to regions of high diversity, as the estimator performs best when applied to communities with a relatively large number of species.

\section{Monitoring at the Base of the Pyramid}

Because ARMI has an explicit mandate to monitor amphibians and assess status and trends on DOI lands, extensive monitoring efforts on a continental scale at the base of the pyramid currently must be a peripheral component of the program. It is clear, however, that efforts on DOI lands will not provide landscape-level data comparable to those obtained from the BBS or from State amphibian atlases. Landscapelevel data are needed for documenting change at regional or landscape levels. Because DOI lands form a nonrandom selection of areas within any region, extensive surveys at the base of the pyramid form a stratum of areas not covered by mid-level monitoring, and they are a critical component of any nationwide summary of amphibian populations.

ARMI intends to collaborate with ongoing landscapelevel programs to provide more intensive information to augment data collected in these programs, to provide methods and analysis advice that can improve these programs, and to assist the coordinators of these programs with data management and summary, whenever possible. Here, we briefly describe three ongoing program elements that have been identified as possible contributors to base-level monitoring, note limitations that could compromise their use as base-level monitoring programs, discuss what information they could bring to an ARMI collaboration as they exist now, and identify what modifications would be needed for the programs to provide valid inferences of distributions and change on a continental scale.

\section{The Amphibian Research and Monitoring Initiative National Atlas for Amphibian Distributions}

The atlas is a county-level compendium of current and historic records of amphibian occurrences compiled by Dr. Michael Lannoo, Ball State University, and his students. A copy of the atlas has been obtained by ARMI (http://www.pwrc.usgs.gov/armiatlas). The species records are from published, peer-reviewed scientific literature; museum records; State and regional herpetological atlases; and other confirmed and validated observations. The atlas includes geographic distribution data (see examples in fig. 3) for all amphibian species currently recognized in the U.S., along with a list of the supporting references used for each species. The atlas is not a monitoring effort and cannot provide the basis for statistical comparisons over regions or times, but it has value as a geographic summary of survey efforts and is useful for illuminating data gaps. The atlas also has considerable value for application with GIS tools to analyze patterns of species distributions, in concert with patterns of known and potential stressors, to develop research hypotheses and provide a first assessment of risk. The atlas provides a convenient structure for future summaries of information at the county level. 

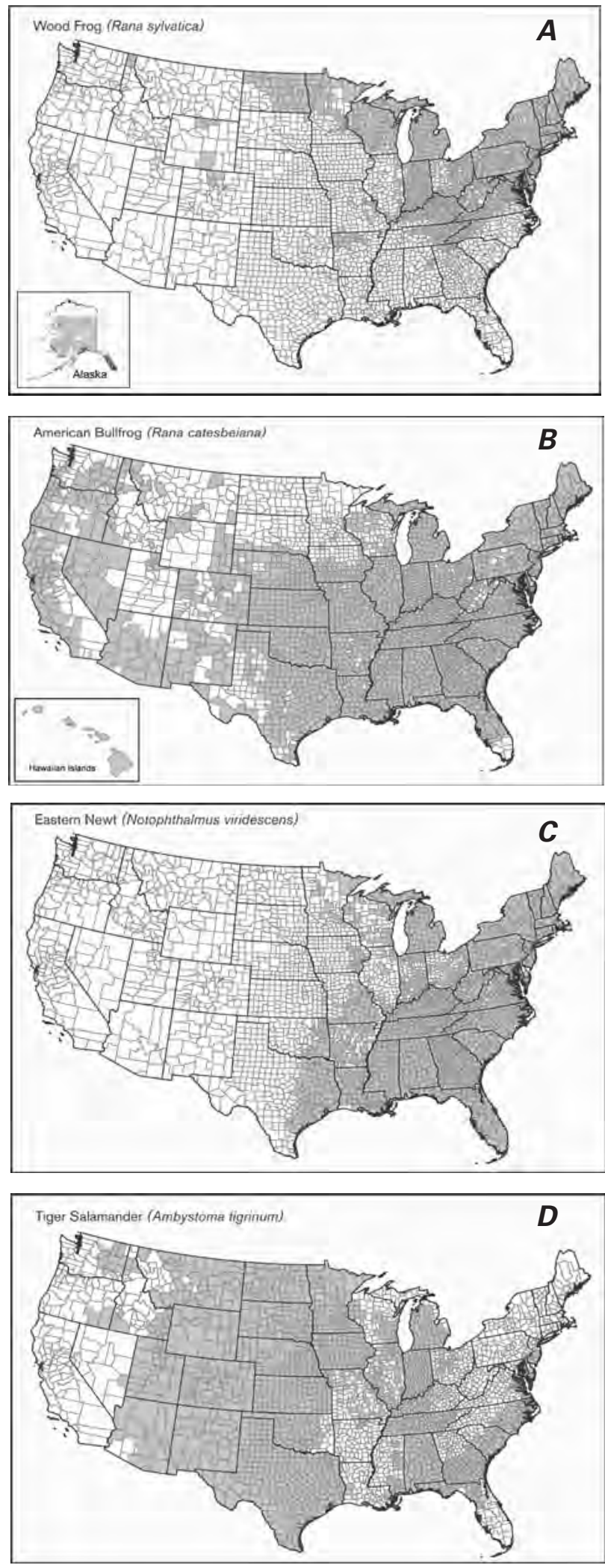

Figure 3. Species distribution map for $A$, wood frog (rana sylvatica); $B$, American bullfrog (rana catesbeiana); $C$, Eastern newt (notophthalmus viridescens); and $D$, tiger salamander (ambystoma tigrinum).

\section{North American Amphibian Monitoring Program}

The North American Amphibian Monitoring Program (NAAMP) is a project in the Inventory and Monitoring Branch of the Patuxent Wildlife Research Center. NAAMP was designed to be directly analogous to the BBS in that it has roadside survey routes and collects an index to animal abundance based on ordered categorical data collected at a series of stops along these routes. The survey approach is limited to regions with calling frogs and is currently implemented in the Midwest and the Northeast regions. Data are collected by volunteers who are recruited by State agencies. Although NAAMP data have the potential to represent broad population patterns operating at the landscape scale, the geographic scope and survey design limit the general applicability of the survey and statistical inference. As with the ARMI National Atlas for Amphibian Distributions, NAAMP can provide information to develop research and monitoring hypotheses and first qualitative assessments.

\section{Frogwatch USA}

Frogwatch USA is an educational frog and toad monitoring program coordinated by the USGS and the National Wildlife Federation (http://www.nwf.org/frogwatchUSA/). Volunteers collect data on breeding calls by amphibians throughout the country. Frogwatch USA lacks a defined sampling frame, and counting procedures are designed to provide minimal data from a series of volunteers who vary greatly in competence. Data entry is Web based and relies on repeated counts by volunteers. Frogwatch USA could be an extremely effective public outreach program, and the goals of the program are mainly educational. With some modification in design, it could provide some valid statistical inference to broader landscapes (MacKenzie and others, 2002).

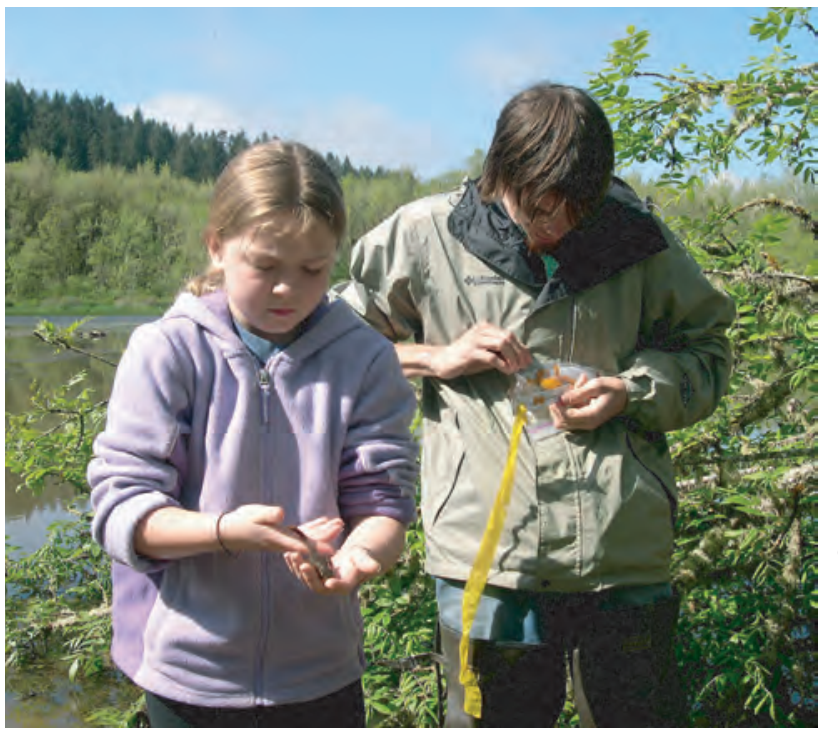


As these three program elements now stand, they could bring to ARMI the following:

- Considerable outreach to the public and professionals who contribute to these programs.

- Frameworks to organize information about actual datacollection activities in the U.S.

- Qualitative data about distribution patterns that could be used to develop research hypotheses and provide a first cut at qualitative assessments of risk and trend.

None of the program elements, however, provide information appropriate for the base-level monitoring needs of ARMI. Base-level requirements include defined sample frames and some means to estimate detection probability. All of the program elements, however, have components that could form the basis of base-level monitoring. ARMI could influence their development by providing protocols for data collection and summary. In particular, the occupancy estimation procedure has application in NAAMP and Frogwatch USA, and Frogwatch USA coordinators are experimenting with this technique in their replicate counts.

\section{North American Reporting Center for Amphibian Malformations}

The USGS Northern Prairie Wildlife Research Center initiated citizen reporting of amphibian malformations through the Web-based North American Reporting Center for Amphibian Malformations (NARCAM). This site is now hosted by the National Biological Information Infrastructure and managed by the University of Georgia's Savannah River Ecology Laboratory (http://frogweb.nbii.gov/narcam/).

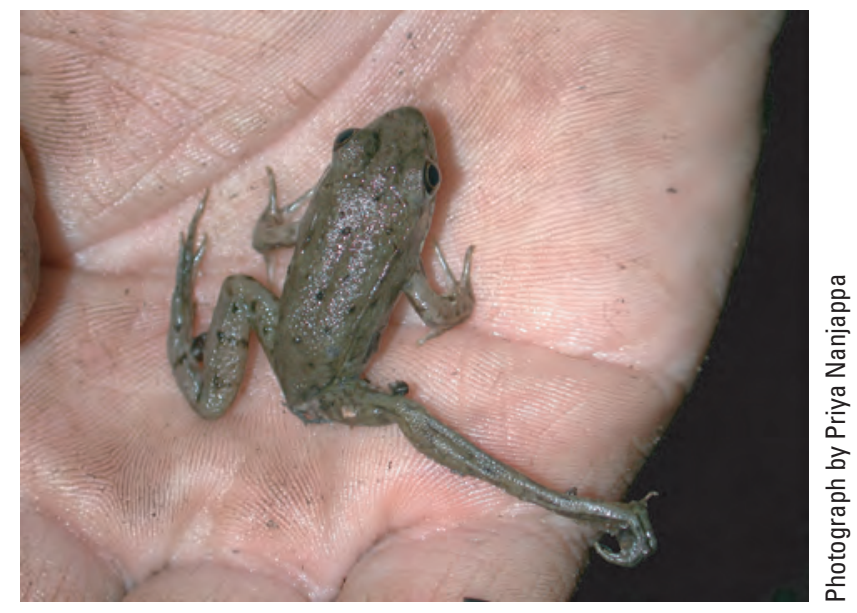

\section{Implementation of Base-Level Monitoring}

ARMI base-level monitoring will consist of a replicate checklists approach in which some national sampling frame is chosen (counties, blocks of area of specified dimensions, and so forth) and well-defined sampling schemes are implemented to provide adequate spatial representation across the landscape and to provide temporal representation to estimate detection probability, and to assess changes over time. The occupancy and species richness estimation procedures used at ARMI midlevel monitoring sites could be implemented at the level of either counties (as in an atlas, with multiple participants collecting information in replicate checklists), NAAMP-style survey routes, or in Frogwatch USA-style nonrandom sites. Also, ongoing State atlases could be incorporated into a dynamic nationwide atlas. All of these approaches have varying levels of scientific control and representation, so their relative roles would have to be specified. Providing an appropriate sample frame and estimation procedure, however, will greatly enhance the quality of information, and the existing administrative structures can be used in these enhanced surveys.

\section{Monitoring at the Apex of the Pyramid}

Monitoring at the apex of the pyramid includes intensive population studies at a small group of selected sites, which, at this stage of implementation, are located on DOI lands, or, if on other lands, receive outside funding. The objectives of these studies will vary, but four types are anticipated:

- Determining demographic and life-history characteristics of key species. Data from these studies will provide information for population modeling efforts targeted to elucidate fundamental population processes specific to species rather than locations. Results from these studies are intended to provide the basic biological information necessary to inform research and monitoring at all levels.

- Relating environmental change to changes in demographic and life-history characteristics over time. These studies are intended to provide the basic biological information necessary to inform research and monitoring at all levels.

- Doing cause-effect studies. As locations with disease, malformations, nonindigenous species, or declines are identified, these sites will provide for progressively more intensive research to identify specific causes. ARMI also anticipates emerging research needs at this level, as resource managers implement management plans and question resultant effects on amphibian populations. Some apex sites already incorporate controlled manipulations designed to determine the effects of potential stressors on amphibian populations. This approach effectively merges the research and monitoring components of ARMI.

- Developing protocol and techniques. Considerable information is needed on the techniques appropriate for sampling some groups of amphibians, and research is necessary before effective monitoring of some species can begin. 


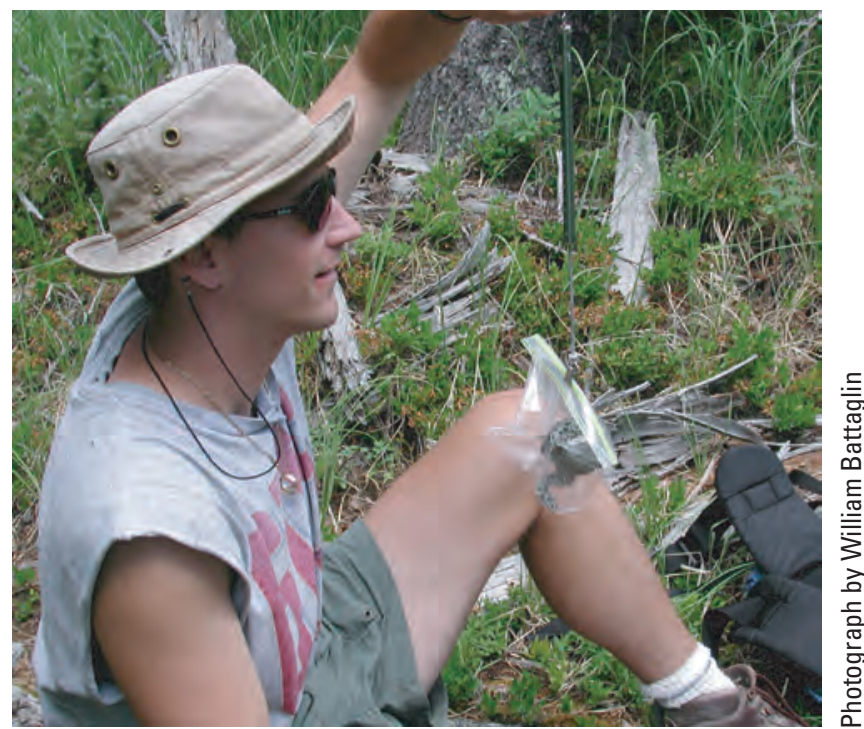

Apex monitoring sites will not be chosen randomly. Some apex sites will be locations where population data already have been collected annually over the past several years. For new apex sites, selection should be based on several criteria. Locations with multiple species are desirable, but single species may be important for compelling reasons (for example, an endangered species). Single breeding sites probably should be avoided in favor of clusters of sites so that metapopulation processes (migration) can be studied. Sites should be generally representative of local amphibian habitats (artificial habitats should be avoided), and some sites should be chosen where potential exists for influences from known or suspected stressors. Logistics for reaching and monitoring the sites also should be a consideration. Apex monitoring sites are good candidates for intensive water-quality monitoring or any monitoring activities that are too expensive to conduct at midlevel monitoring sites.

\section{Research on Causes of Declines}

The causes of amphibian declines are varied and can be complex, and different approaches will be necessary if ARMI is to contribute to this rapidly developing field. Some research will be tactical-short-term research with a well-defined question to address a known problem for persistence of amphibian populations. However, because there are still significant gaps in our knowledge of what is causing the declines of many species, a major, multidisciplinary effort will be necessary to determine environmental factors responsible for the decline or malformation of amphibians. Stresses on amphibian populations come from a variety of sources, both natural and anthropogenic (Halliday and Heyer, 1997; Kiesecker and others, 2001; Krest and others, 2003; Lannoo and others, 2003), and the effects can depend upon life history and habitat of the affected species. The types of stressors amphibians experience and the conditions that foster these stressors involve complex interactions among environmental conditions, including human land management. For example, although acid deposition can cause direct mortality of embryos of some species, other species are quite tolerant of acid conditions. Acidification, however, also increases the degradation of humic acids in water that normally protect aquatic organisms from ultraviolet radiation (Schindler and others, 1996), leading to the possibility that tolerant species could nonetheless be harmed by increased acid deposition. ARMI hopes to gain an understanding of these complexities by bringing together biological, hydrological, geographical, geological, toxicological, and statistical expertise to ensure access to a broad set of analytic approaches and tools.

ARMI will link the monitoring data collected with available and new information about environmental conditions in amphibian habitats and potential sources of amphibian stress (Little and others, 2003). A three-level approach of increasing complexity is proposed to determine relations among environmental conditions, stressors, and amphibian population declines. This approach includes tier 1-an initial survey of environmental conditions and potential stressors; tier 2experimentally based causal research to evaluate the effects of stressors on amphibians, with emphasis on evaluation of multiple stressors; and tier 3-evaluations of the relative risk from multiple stressors and recommendations for remediation.

\section{Tier 1 Assessments}

The objectives of tier 1 assessments are to evaluate existing information related to potential stressors at ARMI baselevel, mid-level, and apex monitoring sites. This will begin the process of evaluating stressors that may cause harm to amphibian populations. The focus of tier 1 assessments will be an evaluation of potential stressors (Little and others, 2003) conducted at mid-level and apex monitoring areas across the Nation.

Tier 1 assessments will include both desktop and onsite activities. From the desktop, ARMI regional coordinators will have access to existing Federal and non-Federal data, including information on land use and land cover, climate, chemical use, soils, and sources of pollution (Box C). These data will be accessed via a GIS-enabled Web application that will make it easy for ARMI researchers to view, query, and download information for the monitoring areas or sampling units of interest. The benefits of a Web-served tier 1 database are: (1) New data and updates are readily available to users; (2) functionality of the Web application can continue to grow with advances in interactive Web technology; (3) physical data media (for example, CDs and DVDs) and associated costs for production and distribution are avoided; and (4) dynamic access to external data sets is possible through a worldwide digital geographic data network. These benefits are particularly important for a monitoring program, where data collection is a continuing process.

Tier 1 assessments also can include in-the-field measurement of a range of environmental variables, including current habitat and weather conditions, water quality, and surveys 


\section{Tier 1 Investigation into Stressors Associated with Amphibian Declines}

In December 2001, the ARMI task force on stressors research presented a report outlining a three-tiered approach to investigate potential environmental factors contributing to amphibian declines and malformations. The broadest tier suggested a synoptic evaluation of existing environmental data to identify factors exhibiting spatial autocorrelation with geographic patterns of declines. This coarse-level evaluation would support development of research hypotheses through the compilation of a national database of amphibian decline response and potential predictor variables within a GIS framework. The ARMI program funded this approach in August 2002, and an environmental stressors team was formed. The team members are: Carl Korschgen and Jennifer Hamilton, Columbia Environmental Research Center; Alisa Gallant, EROS Data Center; William Battaglin, USGS Colorado Water Science Center; and Pat Anderson, Biological Status and Trends.

The objectives of the team are to: (1) Assist in coarse-filter analysis of relations between amphibian declines and environmental stressors, (2) compile a geospatial database of potential amphibian stressor predictor and response variables that will support this effort and more intensive analyses, and (3) develop a Web-enabled application to facilitate database analysis by providing user-interactive mapping and data download capabilities. Candidate stressors include:

\section{Stressor Category-Habitat}

Habitat quality

Extent and fragmentation of habitat

Water supply (hydroperiod)

Food web

Land-cover and land-use changes

Urbanization

Agriculture Silva and culture

Water source and quality

Wildland fires

Construction (for example, roads, agriculture, private or commercial development)

\section{Stressor Category-Climate}

Historic and long-term climate

Departures from long-term averages for:

Precipitation

Temperature

Snow Accumulation

Timing of freeze/thaw

Current climatic conditions

Departures from monthly mean precipitation and temperature

Increase/decrease in mean temperature

Winter degree days, number of days above freezing

Dates of first freeze and thaw

Prevailing wind direction

Humidity

Frequency and amount of rainfall

Flooding, droughts, and other extreme events

Ultraviolet radiation

Changes in cloud cover

Presence of vegetative cover or shading

Climate-change effects

\section{Stressor Category-Biotic}

Interspecific competition

Nonindigenous species

Native species

Predation

Disruption of food chain

Loss of food-chain organisms

Disruption of community dynamics

Regulating processes

Keystone species

Commensalism

\section{Stressor Category-Disease}

Infectious diseases

Known distribution factors that increase the success of the pathogen

Carrier stages or carrier organisms

\section{Stressor Category-Chemical}

Chemical usage

Proximity to contaminant sources (for example, agricultural crops, town dumps)

Influence from point source pollution (for example, proximity to industrial area)

Aquatic pathways

Water-quality characteristics

Nutrients, $\mathrm{pH}$, acid-neutralizing capacity, ions

Turbidity and dissolved organic carbon content of water

Geologic characteristics

Soils, sediments, metals, $\mathrm{pH}$

Air quality

Acid deposition

Smoke, smog 
for nonindigenous species and disease or parasitism. Tier 1 assessments will be conducted at selected monitoring sites in mid-level and apex-level monitoring areas, providing the basis for developing hypotheses about causes of amphibian decline or malformation. If resources permit, tier 1 assessments also will be extended to base-level monitoring sites, providing a foundation for data analysis at the regional or national scale.

\section{Tier 2 Assessments}

The objectives of tier 2 assessments are to determine the cause(s) of observed amphibian declines or malformations, to identify the stressors that lead to the harmful conditions, and to propose a management strategy to mitigate the problem. The analysis of tier 2 assessments will result in the definition of new or critical variables to be collected at mid-level and apex monitoring sites. Tier 2 assessments will include manipulative laboratory and field experiments, comparative monitoring, and analysis of amphibian data in conjunction with information on local or regional stressors (Little and others, 2003).

Tier 2 assessments will consist of hypotheses-driven experimental research in each region (for example, do chemicals that have sublethal effects on individual animals affect the persistence of populations?). Targeted stressors data will be collected concurrently with amphibian data to test the hypotheses. Tier 2 assessments will emphasize the evaluation of multiple stressors, each of which may cause harm to amphibian populations. This process will result in the identification of a large number of potential stressors and will attempt to determine their relative importance. Once a particular stressor is implicated in amphibian decline, that stressor will be incorporated into ARMI's broader scale monitoring efforts.

Identification of potential stressors from tier 1 studies will be followed up by more specific studies of greater complexity. Likewise, the monitoring of potential stressors would begin with rapid, low-cost methods, such as toxicity tests with common test species or enzyme-linked immunosorbent assays (ELISA) to detect pesticide residues, and then proceed to more complex or costly methods.

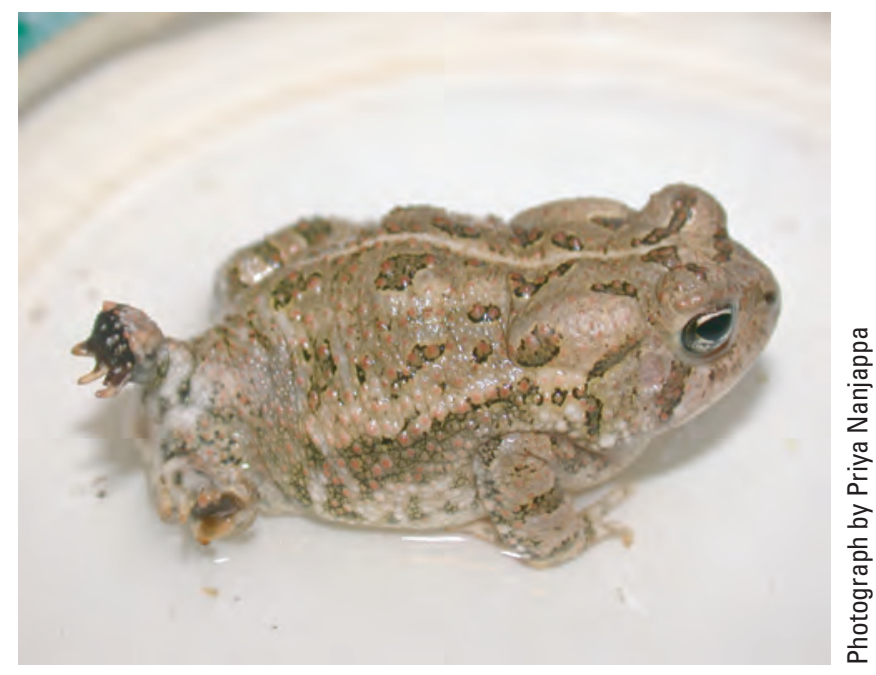

\section{Tier 3 Assessments}

The objective of tier 3 assessments is to provide models that predict when and where amphibian species or habitats are at risk at a local, regional, or national scale. Tier 3 assessments will build on the information and understanding gained from tier 1 and tier 2 assessments. Information generated by the research will be used to develop and test habitat restoration or management strategies. Tier 3 assessments will provide an iterative decision-support process that will include probabilistic risk-assessment models of stressor effects on amphibian species, margins of error for injury, and focused monitoring of previously identified amphibian stressors. This type of analysis can be used to evaluate the relative risk of injury posed by a specified change in some environmental condition to all species in a sampling frame.

Although ARMI currently devotes funding to studies into the causes of declines, these studies are limited by the funding available to short-term, highly focused research on limited topics. Implementing the broader strategic research described herein will be difficult without additional funding (Box D).

\section{Methods and Protocol Development}

Sound methods for monitoring, assessing, and synthesizing information on amphibian populations are needed to meet ARMI objectives. As new methods are implemented, protocols should be documented to ensure consistency in application. Methods and protocols are important products to offer potential partners to help expand monitoring beyond DOI lands.

Methods development and protocol documentation will be a continuing process as ARMI evolves (Box E). Due to the diversity of amphibians, habitats, and risk factors, development of methods and protocols for an integrated program is complex. As results accumulate, new research directions are expected to emerge requiring adjustments to existing methods and protocols. To maintain the ARMI at the forefront of amphibian monitoring, appropriate new techniques, technology, analyses, and models will be incorporated into the program.

Methods development in the ARMI is in progress in eight categories: (1) Amphibian monitoring; (2) stressors monitoring; (3) trend analysis and correlation; (4) population, landscape, and stressors modeling; (5) geospatial information applications; (6) management decision-support tools; (7) database management structure, input, and output; and (8) metadata. Communication among the various groups developing methods and protocols will be critical to the integration of ARMI. Methods and protocols should be structured to enable researchers to meet ARMI goals. It should be clear how the methods and protocols contribute to the ability to address questions such as: What is the expected information 


\section{Stressors and Causal Research: Recommendations and Challenges}

\section{Recommended Actions}

- Develop tier 1 assessment procedures to ensure uniformity in the evaluation of habitat conditions relative to physical, chemical, and biotic variables that are potentially harmful to amphibians. Identify sources of information and create a database tool to organize, manage, and serve the data to ARMI researchers.

- Initiate prototype projects that focus on amphibian habitats that appear to be impacted by a dominant stressor, such as contamination, disease or parasitism, physical habitat alteration, and(or) nonindigenous species. Use these projects to illustrate how to diagnose a multiple stressor problem. Form research teams to assist ARMI coordinators with site assessments and to conduct studies in support of the prototype projects.

- Form a working group(s) to identify, prepare, and organize protocols for research methods, such as for pathogens, contaminants, biotic indices of injury, and so forth.

\section{Challenges to Implementation}

- Funding for research in the ARMI program is limited, and allocation of resources in the most efficient way will require considerable oversight and evaluation. Evaluation of any stressor at ARMI sites across the nation will be expensive.

- DOI lands may not be the ideal location for some causal research because they lack some stressors (for example, urban development or agricultural use) that are common on non-DOI lands.

\section{Methods and Protocols Development: Recommendations and Challenges}

\section{Recommended Actions}

- Form a technical committee to facilitate communication, feedback, and consistency in methods development.

- Maintain an interactive Web site that stores information about currently applied data-collection and management protocols and reports of ongoing research on new methods and protocols.

- Allocate funding to support development of observational, statistical, and analytical techniques for amphibian monitoring.

- Provide an outlet for publishing data-collection protocols and metadata.

\section{Challenges to Implementation}

- Limited communication between the ARMI components and disciplines impedes collaboration.

- Diversity of amphibian life histories and habitats makes application of uniform and unbiased methods difficult.

- Diversity of the range and types of methods and protocols in this program (for example, in the eight areas identified) makes it difficult to keep everyone abreast of the most current information. 
content of the data collected? How can the data be analyzed? How can the analyses address the major questions? How can all available analyses and information be synthesized into a broader understanding of amphibian issues? What are the limitations of the data, analyses, and syntheses in addressing amphibian issues? To integrate new collaborators, ARMI will strive to anticipate and develop methods and protocols compatible with the needs of our partners. Therefore, it also will be important to structure methods and protocols such that ARMI can adapt to emerging amphibian issues and incorporate new techniques that can better analyze and interpret historical and future monitoring data.

\section{Database Development}

Two national databases are associated with ARMI. One, the ARMI National Database, is a relational database that houses the ARMI field-survey data (Box F). This database will store amphibian survey data, including information about sampling methods, species observed, habitat, water chemistry, and additional related parameters. The database will feature Web-based data retrieval, allowing researchers, cooperators, and the public to view these data via the Web. Another database, the ARMI Atlas for Amphibian Distributions, represents a county-level (subcounty level for some States) compendium of historic to current species presence documented for all amphibian species known to occur in the U.S. Construction of amphibian distribution maps for the atlas began in 1999, with the compilation of documented records of presence from scientific literature, museum records, and regional expertise, to accompany the book "Amphibian Declines-The Conservation Status of United States Species" (Lannoo, 2005). A copy of this original database was acquired by ARMI. The ARMI Atlas Web site features photographs and distribution maps for all amphibian species known to occur in the U.S. (http://www.pwrc.usgs.gov/armiatlas/).

An integrated national database will have several benefits. ARMI investigators will have fewer data-management responsibilities - the relational database will be created and maintained for them. The ability to easily query these data sets should expedite data analyses. This data-management process should facilitate collaborative efforts among ARMI investigators and between ARMI scientists and the herpetological research community. Investigators will be able to readily identify the locations and goals of ongoing studies so that duplicity can be avoided while activities at nearby locations can be better coordinated. The availability of new results frequently leads to additional questions that require more research, allowing investigators to quickly add components to ongoing studies that would address these questions. Improved communication among investigators should result in faster response to management needs.

\section{Databases}

\section{Recommended Actions}

- The national database must have the flexibility to allow differences among regions in the types of data collected and to allow a variety of different analyses. During the continuing development of the database, other models, such as a modular network (Baker and others, 2000), needs to be given consideration.

- ARMI principal investigators need to take an active role in developing the implementation of the database.

- ARMI database developers need to be in frequent communication with principal investigators.

\section{Challenges to Implementation}

- The variety of data collected among the different regions means that the database will be complex and difficult to manage.

- Assimilation of regional data sets has been slower than anticipated.

For land managers and administrators, this datamanagement process should improve access to timely information. Rapid access to information is becoming a necessity, allowing managers to more effectively initiate proper conservation and management activities on the ground, to the benefit of the amphibian communities. Amphibian populations have been shown to change dramatically during relatively short periods of time, and access to current information can be critical for identifying and implementing appropriate management actions for these taxa.

\section{Analysis and Reporting}

Analyses will be conducted to assess the status and trends of amphibian populations, to determine biotic and abiotic stressors, and to improve understanding of the relations between amphibians and the environment (Box G). Different mechanisms for reporting these results can be used to provide regional and national syntheses; to provide feedback for determining whether changes in protocols, monitoring strategies, and(or) research activities should be considered; and to provide decision-support tools for land managers and policymakers. 
Reports will include descriptions of field and laboratory research, regional and national status and progress reports, methods and protocol documentation, field-survey raw data and summaries, and administrative summaries regarding operational challenges and integration of partners. Forms of reporting will include peer-reviewed journal articles, USGS publications, administrative reports, maps, factsheets, oral presentations, posters, and Web pages.

ARMI regional coordinators will be responsible for conducting analyses and compiling reports. Regional differences in environmental complexities, site availability and(or) access, species richness, and complexity in sample designs virtually ensure that the scope of these responsibilities and the analyses will vary by region. Communication among regional coordinators, national coordinators, and the ARMI steering committee is essential if information collected by ARMI is to be integrated across spatial scales and disciplines.

Some activities will produce nonroutine publications from current ARMI-sponsored research on specific stressorsspecies interactions and from comparison of coarse-scale species distribution patterns with patterns of environmental characteristics. These publications, together with routine summary reports, will provide a broader understanding of factors operating at different scales that affect amphibian conservation.

It will require several years for ARMI to have a fully operational field component and routine analysis and reporting procedures, but the current design is producing immediate results and information. Of the approximately 290 amphibian species in the U.S., and as of the field season of 2003, ARMI has been studying 61 species in mid-level monitoring areas and 62 species at apex monitoring sites-monitoring 84 species overall. In some cases, there are sufficient data to begin examining change in occupancy with time; how many and which species increased, decreased, or remained the same; and if the direction of change can be predicted by environmental conditions at the local level (rainfall, drought, habitat loss). With longer monitoring, ARMI will begin to address ecological processes, including the identification of true declines, stressor effects on population dynamics, and metapopulation dynamics.

\section{Analysis and Reporting: Recommendations and Challenges}

\section{Recommended Actions}

- The team of national ARMI coordinators need to take leadership for coordinating analysis and reporting activities. This interdisciplinary team will determine how to integrate biological, hydrological, geographical, and statistical components into analyses and reports.

- National coordinators need to establish milestones and deliverables with the regional coordinators. Likewise, the regional coordinators need to establish who is responsible for what products and when those products will be available. Data ownership and the schedule for making data available to partners, managers, and the general public also need to be defined.

- Annual national meetings and more frequent conference calls or cyber meetings need to occur to achieve the required level of communication. A national, multidisciplinary program requires frequent communication among participants in order to ensure that program activities support program objectives.

- Periodic external review of program activities and outputs need to be instituted to maintain program relevance and defensibility. ARMI currently has a steering committee comprised of members both external and internal to the USGS that can address this need.

\section{Challenges to Implementation}

- Perhaps the greatest challenge to implementing broad-scale analysis and reporting on amphibian status and trends is the multidimensional complexity of the task. Amphibian monitoring methods can differ by region, by species, and by stage of development, so nationally consistent data-collection methodology is not feasible. Accordingly, sample designs will vary across the country, making consistency in reporting a challenge.

- Communication among ARMI participants is insufficient to meet program objectives. Because of the many responsibilities placed on regional coordinators, communication outside the region has not been given a priority. ARMI national coordinators should work with regional coordinators to decide how best to effect more frequent communication among regional and national coordinators. 
Integrating data from a variety of sources presents a challenge for national reporting, but the data can be interpreted and summarized using an ecoregion framework (Omernik, 1995). Ecoregions are useful environmental units for interpretation and reporting because they represent areas where there are more environmental homogeneity in characteristics such as climate, terrain, geology, soils, vegetation, and land use than occurs across units, and they can be hierarchically scaled as needed. Selection of an appropriate ecoregion framework will stratify the broader scale environmental and human factors affecting amphibians. The ecoregions provide a geographic context for generalizing or extrapolating environmental or stressor data collected at specific monitoring locations to amphibian and environmental data collected elsewhere or at other times within an ecoregion. An ecoregional framework also can be used to establish sites for long-term monitoring and research. Various ecoregion maps have been developed (Bailey, 1995; Omernik and Bailey, 1997; Griffith and others, 1999), but the framework developed by Omernik (1995) best incorporates the human interaction with the environment. A challenge facing ARMI is that Federal lands are generally not representative of the ecoregion where they occur. Most Federal lands were so designated because they are unique in some way and were not perceived to be amenable to early economic development.

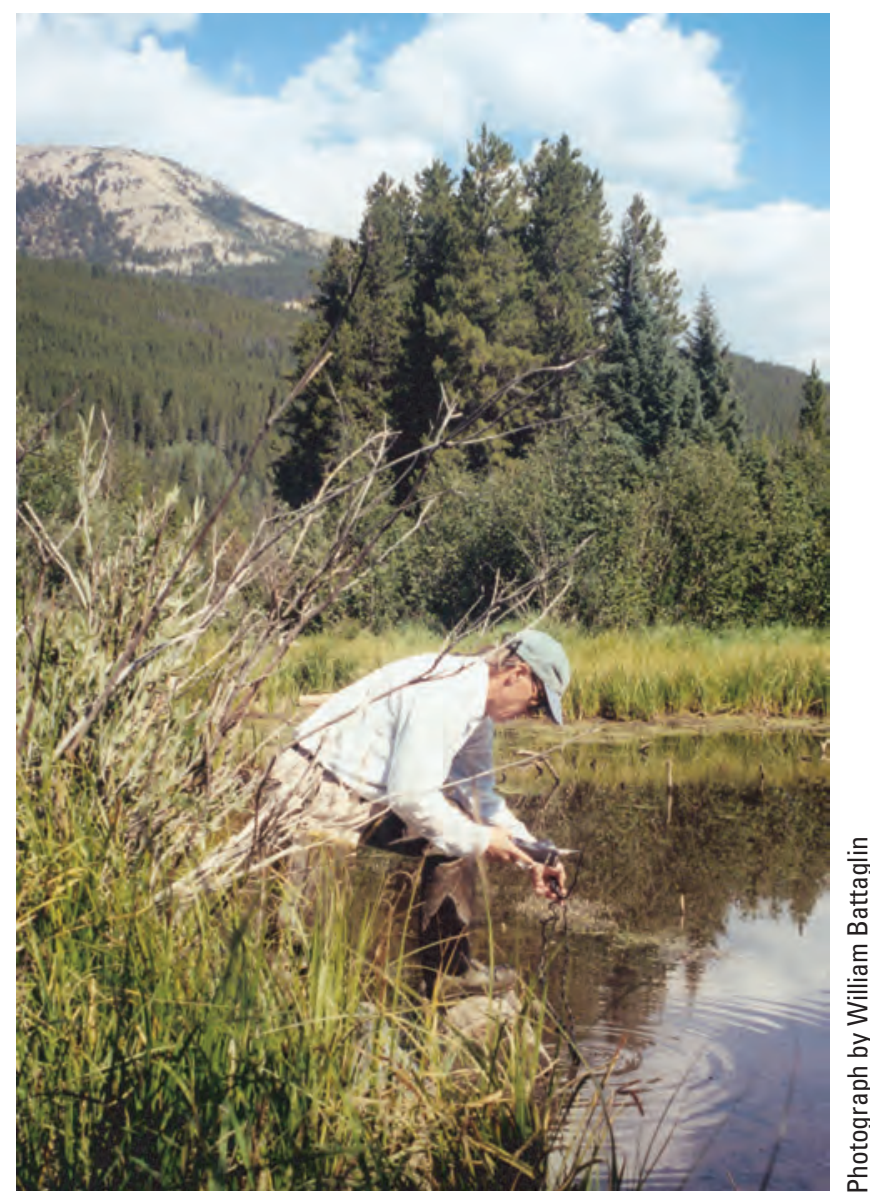

Despite the necessity of using a wide variety of sampling techniques and designs, ARMI monitoring data will be comparable across the country for mid-level and apex monitoring areas. For mid-level monitoring areas, direct estimates of occupancy only will be comparable among monitoring areas that use the same sampling units (for example, ponds). Trends in occupancy, however, can be compared and summarized among all species and all mid-level monitoring areas across the country. This will allow both regional and national tabulations on the proportion of species that are declining in mid-level monitoring areas. These tabulations, in turn, can be compared over time to track the status of amphibians regionally and nationally. Similarly, trends in amphibian abundance in apex monitoring areas can be summarized and tracked despite a wide range of methodology.

Some ARMI reporting will encourage participation by collaborators. By widely sharing information on the methods and protocols developed for ARMI, the program can indirectly influence the way in which data are collected by other researchers. The ARMI public Web site (http://armi.usgs.gov/) is available to encourage information sharing.

ARMI also will encourage partnerships through reciprocal exchange. While ARMI collects data on amphibians at sites under the jurisdiction of the partners, the partners will gain access to protocols that ARMI has developed and(or) to the ancillary environmental data that ARMI has compiled for the partners' sites. Additionally, ARMI's broader geographic scope will provide the partners with a regional or national context from which to compare their own sites.

\section{Partners and Leadership}

Building relationships with partners is a major component of the ARMI program (Box H). ARMI partners in the DOI, the USFWS, the NPS, and the BLM, have long looked to the USGS for assistance with monitoring amphibians on Federal lands. These agencies also need status and trends information about U.S. amphibians to set land-management policy. Other Federal partners, such as the U.S. Environmental Protection Agency (USEPA), the USDA Forest Service, and the USDA Natural Resources Conservation Service, and State partners also can utilize the information ARMI collects to make decisions about environmental regulations, land management, conservation incentive policies, and landowner education needs. Implementation of the ARMI will be greatly enhanced by cooperative relationships with State agencies (Departments of Natural Resources), State herpetological societies, and amphibian education and conservation organizations such as the Declining Amphibian Populations Task Force (http://www.open.ac.uk/daptf/) and Partners for Amphibian and Reptile Conservation (http://www.parcplace.org/). There are a multitude of organizations, academic institutions, and agencies concerned with amphibian conservation (see Web sites listed above). 


\section{Partnerships, Leadership, and Integration: Recommendations and Challenges}

\section{Recommended Actions}

- Priorities should be set to identify individuals responsible for national components of the program and to set time lines for implementation and deliverables. Resouces should be allocated according to established priorities.

- Communication should be initiated by ARMI regional coordinators with the partners in each region, and periodic meetings should be held to share information on research and monitoring activities to advance the understanding of status, trends, and threats to amphibians.

- Products should be developed, such as Web sites and a survey database, that will engage the partner agencies and States in contributing to the monitoring effort.

- Information should be exchanged by ARMI with other Federal agencies engaged in monitoring efforts. Information on the experiences, successes, and failures of other national monitoring programs could save valuable resources.

- University research partners with herpetological expertise should be sought out by ARMI. ARMI coordinators can facilitate amphibian research through funding opportunities regionally and nationally.

- A unified set of methods and analyses for all amphibian monitoring and research in the USGS should be developed to increase communication within and outside of ARMI.

\section{Challenges to Implementation}

- The wide diversity of potential partners, within and across regions, will challenge the organizational and communication skills of the ARMI coordinators.

- Building an integrated partner network will require effort from all partners, including USGS, and will take time to develop.

- The responsibility for protection and conservation of amphibian populations resides with the States and must be respected and recognized by ARMI. All research and monitoring efforts must abide by State laws for scientific research permits, specimen collection, and reporting.

- Many ARMI researchers have other research or administrative duties that keep ARMI duties from being a first priority.

Partnerships are important at every level of the monitoring pyramid. As a first priority, ARMI is working with DOI land-management partners to identify Federal lands for establishing mid-level monitoring areas. As ARMI matures, non-Federal partners, such as States and nongovernmental organizations, may choose to participate by collecting similar data from a broad range of Federal and non-Federal sites.

At the base of the pyramid, partnerships are critical for collecting information on status and trends of amphibian populations across the landscape. State agencies have the primary responsibility for managing amphibian populations, except for those species federally listed as threatened or endangered. These agencies, therefore, are important partners for broad-based data collection. Many State agencies already are engaged in amphibian atlas projects or are implementing frog and toad calling surveys in collaboration with the NAAMP. The public can directly contribute observations that may provide useful monitoring information via the Frogwatch USA project or report on amphibian malformations using NARCAM. At the apex of the pyramid are intensive, long-term monitoring sites and sites with long-term active research. Some of these include the PRIMENET sites located within the national parks (http:// www.forestry.umt.edu/research/MFCES/programs/primenet/). The NPS and the USEPA have been engaged in long-term monitoring of national parks for ecosystem stressors since 1996. Universities and other individuals and agencies also have engaged in intensive research, and occasionally, monitoring of specific sites (Lannoo, 1996). 


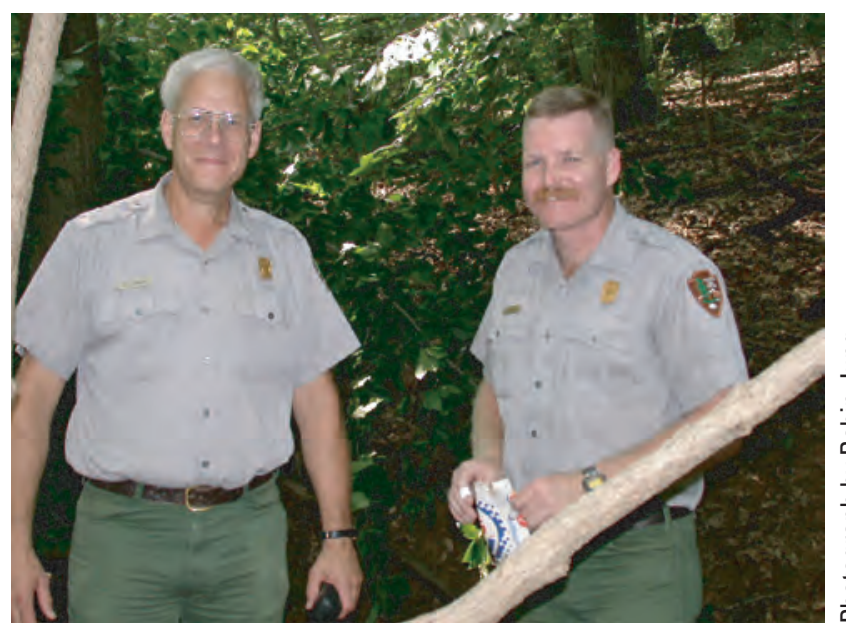

The ARMI will develop collaborative relations with agencies and organizations possessing valuable broad-based data and expertise and will explore ways to integrate this information into regional and national status and trends reports for amphibians. Information developed through the ARMI program should be relevant and useful to partner agencies and organizations charged with land management and conservation of amphibian populations.

International partnerships may provide an important context for the information collected within ARMI. Many factors contributing to amphibian disease, declines, and malformations may not be limited to the U.S. or North America (Green, 1997).

Because of its strong commitment to partnerships, the ARMI has convened a steering committee composed of members from academia, State and Federal research and resource-management agencies, and other interested organizations (see http://armi.usgs.gov/region.asp\#nationalsteering). The steering committee will advise and provide recommendations to the ARMI program and its principal investigators on the direction of the program, research and monitoring priorities, reporting requirements, and development of partnerships. The chairperson will be the principal liaison between the steering committee and the Assistant Wildlife and Terrestrial Resources Program Coordinator, who is the ARMI Program Coordinator. The ARMI Program Coordinator will work with the ARMI coordinators for Biology, Water, and Mapping to provide oversight and leadership for the program.

\section{Integration}

The objectives and scope of ARMI are ambitious and complex, but they are necessary to address the complex ecological and management issues of amphibians. The conceptual designs outlined by this report are in various stages of implementation and, in some instances, have been in operation for several years. Integration will be the key to realizing a fully functional ARMI program.
Integration must proceed in multiple directions-across regions, across disciplines, across the levels of the ARMI pyramid, and across time. Ideally, ARMI will evolve into an integrated and adaptive research and monitoring program, working continuously to refocus, refine, or redirect its questions as results accumulate or new issues emerge. A designated science coordinator at the national level would ensure that these needs are met and could help maintain an appropriate scientific balance between continuation of past monitoring efforts and flexibility for implementation of new directions.

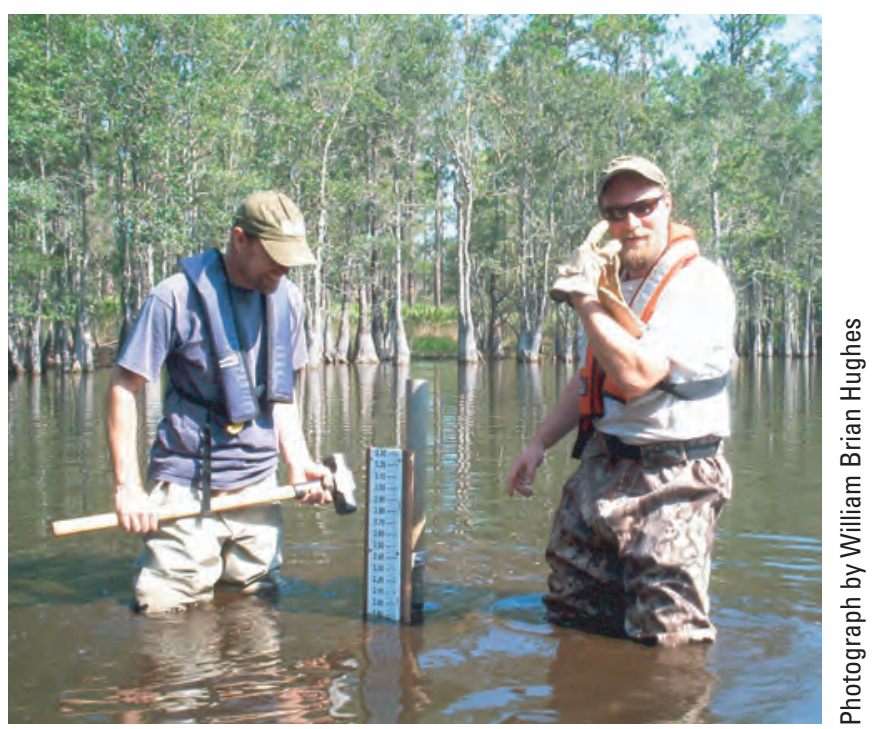

The conceptual designs described in this report for amphibian monitoring and stressors research should give ARMI the flexibility to become an adaptive program. Amphibian monitoring is focusing on a national approach at the mid-level of the pyramid using methods and protocols that allow regional principal investigators to tailor their activities to local amphibian communities and habitats, while providing comparable amphibian metrics and easy transferability to new partners. The proposed statistical estimators address key biological issues and use stressors data to model and test hypotheses of cause-effect. Stressors monitoring and research are focused on a tiered approach to first broadly identify stressors at a national and regional level, then focus investigations at the local level to the most likely candidates, and finally apply hypotheses-driven research and modeling efforts. This tiered approach to identifying the causes of decline or malformations has considerable flexibility and adaptability.

Achieving integration, however, will not be easy due to the complexity of the Initiative. Coordinating the component parts into a well-integrated national program will require the full-time efforts of more than one individual. As partners come into the program and data accumulate for processing, analysis, and reporting, the integration of the program will grow in complexity. It is critical to anticipate ARMI needs for the near and distant future and to begin to strengthen the infrastructure for national coordination and integration. 


\section{References Cited}

Alford, R.A., Dixon, P.M., and Pechmann, J.H.K., 2001, Global amphibian population declines: Nature, v. 412, p. 499-500.

Alford, R.A., and Richards, S.J., 1999, Global amphibian declines-A problem in applied ecology: Annual Review of Ecology and Systematics, v. 30, p. 133-165.

Anderson, D.R., 2001, The need to get the basics right in wildlife field studies: Wildlife Society Bulletin, v. 29, p. 1294-1297.

Anderson, D.R., 2003, Response to Engeman-Index values rarely constitute reliable information: Wildlife Society Bulletin, v. 31, p. 288-291.

Bailey, L.L., Simons, T.R., and Pollock, K.H., 2004, Estimating site occupancy and species detection parameters for terrestrial salamanders: Ecological Applications, v. 14, p. 692-702.

Bailey, R.G., 1995, Description of the ecoregions of the United States, 2d ed.: Washington, D.C., USDA Forest Service, Miscellaneous Publication 1391.

Baker, K.S., Benson, B.J., Henshaw, D.L., Blodgett, D., Porter, J.H., and Stafford, S.G., 2000, Evolution of a multisite network information system-The LTER information management paradigm: BioScience, v. 50, p. 963-978.

Berven, K.A., and Grudzien, T.A., 1990, Dispersal in the wood frog (Rana sylvatica) - Implications for genetic population structure: Evolution, v. 44, p. 2047-2056.

Boulinier, T., Nichols, J.D., Hines, J.E., Sauer, J.R., Flather, C.H., and Pollock, K.H., 1998, Higher temporal variability of forest breeding bird communities in fragmented landscapes: Proceedings of the National Academy of Sciences, U.S.A., v. 95, p. 7497-7501.

Bury, R.B., and Whelan, J.A., 1984, Ecology and management of the bullfrog: Washington, D.C., USDI Fish and Wildlife Service, Resource Publication 155, 23 p.

Cam, E., Nichols, J.D., Sauer, J.R., Hines, J.E., and Flather, C.H., 2000, Relative species richness and community completeness-Avian communities and urbanization in the mid-Atlantic states: Ecological Applications, v. 10, p. 1196-1210.

Caughley, G., and Sinclair, A., 1994, Wildlife ecology and management: Cambridge, Massachusetts, Blackwell Science.

Collins, J.P., and Storfer, A., 2003, Global amphibian declinesSorting the hypotheses: Diversity and Distributions, v. 9, p. 89-98.
Committee on Environment and Natural Resources, 1997, Integrating the Nation's environmental monitoring and research networks and programs-A proposed framework: National Science and Technology Council's Committee on Environment and Natural Resources Report, 103 p. Accessed February 2001 at http://www.epa.gov/cludygxb/ pubs.html

Engeman, R.M., 2003, More on the need to get the basics right-Population indices: Wildlife Society Bulletin, v. 31, p. 286-287.

Erwin, R.M., Nichols, J.D., Eyler, T.B., Stotts, D.B., and Truitt, B.R., 1998, Modeling colony-site dynamics-A case study of gull-billed terns (Sterna nilotica) in coastal Virginia: The Auk, v. 115, p. 970-978.

Gill, D.E., 1978, The metapopulation ecology of the redspotted newt, Notophthalmus viridescens (Rafinesque): Ecological Monographs, v. 48, p. 145-166.

Green, D.M., 1997, Perspectives on amphibian population declines-Defining the problem and searching for answers, in Green, D.M., ed., Amphibians in decline-Canadian studies of a global problem: St. Louis, Missouri, Society for the Study of Amphibians and Reptiles, Herpetological Conservation, v. 1, p. 291-308.

Green, D.M., 2003, The ecology of extinction-Population fluctuation and decline in amphibians: Biological Conservation, v. 111, p. 331-343.

Griffith, G.E., Omernik, J.M., and Woods, A.J., 1999, Ecoregions, watersheds, basins, and HUCs- - How state and Federal agencies frame water quality: Journal of Soil and Water Conservation, v. 54, p. 666-677.

Halliday, T.R., and Heyer, R., 1997, The case of the vanishing frogs: Accessed March 2000 at http://www.techreview.com/ articles/mj97/halliday.htm

Hanski, I., and Gilpin, M.E., eds., 1996, Metapopulation biology—Ecology, genetics, and evolution: San Diego, California, Academic Press.

Hines, J.E., Boulinier, T., Nichols, J.D., Sauer, J.R., and Pollock, K.H., 1999, COMDYN—Software to study the dynamics of animal communities using a capture-recapture approach: Bird Study 46 (suppl.), S209-S217.

Houlahan, J.E., Findlay, C.S., Schmidt, B.R., Meyer, A.H., and Kuzmin, S.L., 2000, Quantitative evidence for global amphibian population declines: Nature, v. 404, p. 752-755.

Joly, P., Miaud, C., Lehmann, A., and Grolet, O., 2001, Habitat matrix effects on pond occupancy by newts: Conservation Biology, v. 15, p. 239-248. 
Kareiva, P., Skelly, D., and Ruckelshaus, M., 1997, Reevaluating the use of models to predict the consequences of habitat loss and fragmentation, in Pickett, S.T.A., Ostfeld, R.S., Shachak, M. and Likens, G.E., eds., The ecological basis of conservation: New York, Chapman and Hall, p. 156-166.

Kiesecker, J.M., Blaustein, A.R., and Belden, L.K., 2001, Complex causes of amphibian population declines: Nature, v. 410, p. 681-684.

Krest, S.K., Linder, G., and Sparling, D.W., 2003, The role of multiple stressor causes in declining amphibian populationsA wingspread workshop summary, in Linder, G., Krest, S., Sparling, D., and Little, E., eds., Multiple stressor effects in relation to declining amphibian populations: Bridgeport, New Jersey, American Society for Testing and Materials STP1443, p. 207-218.

Lannoo, M.J., 1996, Okoboji wetlands: Iowa City, University of Iowa Press.

Lannoo, M.J., ed., 2005, Amphibian declines-The conservation status of United States species: Berkeley, University of California Press.

Lannoo, M.J., Sutherland, D., Jones, P., Rosenberry, D., Klaver, R., Hoppe, D., Johnson, P., Lunde, K., Facemire, C., and Kapfer, J., 2003, Multiple causes for the malformed frog phenomenon, in Linder, G., Krest, S., Sparling, D., and Little, E., eds., Multiple stressor effects in relation to declining amphibian populations: Bridgeport, New Jersey, American Society for Testing and Materials STP1443, p. 233-262.

Linder, G., Krest, S.K., and Sparling, D.W., eds., 2003, Amphibian decline-An integrated analysis of multiple stressor effects: Pensacola, Florida, SETAC Press.

Little, E.E., Bridges, C.M., Linder, G., and Boone, M., 2003, Establishing causality in the decline and deformity of amphibians-The amphibian research and monitoring initiative model, in Linder, G., Krest, S., Sparling, D., and Little, E., eds., Multiple stressor effects in relation to declining amphibian populations: Bridgeport, New Jersey, American Society for Testing and Materials STP1443, p. 263-277.

MacKenzie, D.I., and Kendall, W.L., 2002, How should detection probability be incorporated into estimates of relative abundance?: Ecology, v. 83, p. 2387-2393.

MacKenzie, D.I., Nichols, J.D., Hines, J.E., Knutson, M.G., and Franklin, A.B., 2003, Estimating site occupancy, colonization, and local extinction when a species is detected imperfectly: Ecology, v. 84, p. 2200-2207.

Mackenzie, D.I., Nichols, J.D., Lachman, G.B., Droege, S., Royle, J.A., and Langtimm, C.A., 2002, Estimating site occupancy rates when detection probabilities are less than one: Ecology, v. 83, p. 2248-2255.
Marsh, D.M., and Trenham, P., 2001, Metapopulation dynamics and amphibian conservation: Conservation Biology, v. 15 , p. $40-49$.

Meteyer, C.U., 2000, Field guide to malformations of frogs and toads: Reston, Virginia, U.S. Geological Survey, Biological Science Report USGS/BRD/BSR-2000-0005, $18 \mathrm{p}$.

Meyer, A.H., Schmidt, B.R., and Grossenbacher, K., 1998, Analysis of three amphibian populations with quartercentury long time-series: Proceedings of the Royal Society of London B 265, p. 523-528.

Nichols, J.D., and Conroy, M.J., 1996, Estimation of species richness, in Wilson, D.E., Cole, F.R., Nichols, J.D., Rudan, R., and Foster, M.S., eds., Measuring and monitoring biodiversity - Standard methods for mammals: Washington, D.C., Smithsonian Institution Press, p. 226-234.

Nichols, J.D., Boulinier, T., Hines, J.E., Pollock, K.H., and Sauer, J.R., 1998a, Estimating rates of local species extinction, colonization, and turnover in animal communities: Ecological Applications, v. 8, p. 1213-1225.

Nichols, J.D., Boulinier, T., Hines, J.E., Pollock, K.H., and Sauer, J.R., 1998b, Inference methods for spatial variation in species richness and community composition when not all species are detected: Conservation Biology, v. 12, p. 1390-1398.

Omernik, J.M., 1995, Ecoregions-A spatial framework for environmental management, in Davis, W.S., and Simon, T.P., eds., Biological assessment and criteria: Boca Raton, Florida, Lewis Publishers, p. 49-62.

Omernik, J.M., and Bailey, R.G., 1997, Distinguishing between watersheds and ecoregions: Journal of the American Water Resources Association, v. 33, p. 935-949.

Pechmann, J.H.K., Scott, D.E., Semlitsch, R.D., Caldwell, J.P., Vitt, L.J., and Gibbons, J.W., 1991, Declining amphibian populations-The problem of separating human impacts from natural fluctuations: Science, v. 253, p. 892-895.

Schindler, D.W., Curtis, P.J., Parker, B.R., and Stainton, M.P., 1996, Consequences of climate warming and lake acidification for UV-B penetration in North American boreal lakes: Nature, v. 379, p. $705-708$.

Schmidt, B.R., 2003, Count data, detection probabilities, and the demography, dynamics, distribution, and decline of amphibians: Comptes Rendus Biologies 326 (suppl.), p. S119-S124.

Semlitsch, R.D., ed., 2003, Amphibian conservation: Washington, D.C., Smithsonian Press. 


\section{Amphibian Research and Monitoring Initiative: Concepts and Implementation}

Semlitsch, R.D., Scott, D.E., Pechmann, J.H.K., and Gibbons, J.W., 1996, Structure and dynamics of an amphibian community evidence from a 16-year study of a natural pond, in Cody, M.L., and Smallwood, J.A., eds., Long-term studies of vertebrate communities: San Diego, California, Academic Press, p. 217-248.

Sinsch, U., 1992, Structure and dynamic of a natterjack toad metapopulation (Bufo calamita): Oecologia, v. 90, p. 489-499.

Sinsch, U., and Seidel, D., 1995, Dynamics of local and temporal breeding assemblages in a Bufo calamita population: Australian Journal of Ecology, v. 20, p. 351-361.

Sjögren, P., 1991, Extinction and isolation gradients in metapopulations-The case of the pool frog (Rana lessonae): Biological Journal of the Linnean Society, v. 42, p. 135-147.

Sjögren Gulve, P., 1994, Distribution and extinction patterns within a northern metapopulation of the pool frog, Rana lessonae: Ecology, v. 75, p. 1357-1367.

Skelly, D.K., Werner, E.E., and Cortwright, S.A., 1999, Longterm distributional dynamics of a Michigan amphibian assemblage: Ecology, v. 80, p. 2326-2337.
Smith, C.K., and Petranka, J.W., 2000, Monitoring terrestrial salamanders-Repeatability and validity of area-constrained cover object searches: Journal of Herpetology, v. 34, p. 547-557.

Storfer, A., 2003, Amphibian declines-Future directions: Diversity and Distributions, v. 9, p. 151-163.

Stuart, S.N., Chanson, J.S., Fox, N.A., Young, B.E., Rodrigues, A.S.L., Fischman, D.L., and Waller, R.W., 2004, Status and trends of amphibian declines and extinctions worldwide: Science, v. 306, p. 1783-1786.

Thomas, C.D., Cameron, A., Green, R.E., Bakkenes, M., Beaumont, L.J., Collingham, Y.C., Erasmus, B.F.N., Ferriera de Siqueira, M., Grainger, A., Hannah, L., Hughes. L., Huntley, B., van Jaarsveld, A.S., Midgley, G.F., Miles, L., Ortega-Huerta, M.A., Peterson, A.T., Phillips, O.L., and Williams, S.E., 2004, Extinction risk from climate change: Nature, v. 427, p. 145-148.

Vos, C.C., and Stumpel, H.P., 1996, Comparison of habitatisolation parameters in relation to fragmented distribution patterns in the tree frog (Hyla arborea): Landscape Ecology, v. 11, p. 203-214. 


\section{Glossary of Terms and Abbreviations}

A

Amphibian decline When the loss of amphibian populations across their normal range exceeds the rate at which populations are established, or reestablished, resulting in a downward trend in the number of populations.

Amphibian malformation Primary errors in any phase of morphogenesis including cell proliferation, cell migration, differentiation, programmed cell death, or regression of larval structures (Meteyer, 2000).

Apex monitoring area An area, usually a Department of the Interior (DOI) land unit, that contains one or more apex monitoring sites.

Apex monitoring site Handpicked sites for intensive monitoring and research often consisting of egg counts, population estimates, demographic studies, or other detailed population-scale work.

ARMI Amphibian Research and Monitoring Initiative, a program funded by the U.S. Congress in 2000 to determine the status of amphibians in the U.S. and the causes for declines.

\section{B}

Base-level site A site monitored regularly or irregularly for amphibian species presence that can be on DOI land or other lands, or part of an ARMI-funded study, and may include data reported by the public.

\section{C}

Causal research Research into the causes of amphibian decline or malformation.

\section{D}

Detection probability The likelihood that a particular species will be detected during one visit to a sampling site. Animal population monitoring surveys rarely identify all animals present at a sampling site.
M

Mid-level monitoring area A defined area for which a probabilistic sampling design will allow estimates of occupancy to apply. These areas may include individual or multiple parks, refuges, or any other land units where amphibian monitoring will be conducted.

Mid-level monitoring site A site that is selected from a set of potential sites within a mid-level monitoring area with some known probability and is surveyed one or more times for the presence of amphibian species.

\section{0}

Occupancy An unbiased estimate of the proportion of area or sites occupied by a particular amphibian species that incorporates the detectability of the species.

S

Sample frame An area over which occupancy or species-richness data will be analyzed and interpreted. For most ARMI studies, this equates with the mid-level monitoring area. The sample frame defines the range of inference of the data that will be collected and defines the sampling units.

Sample sites and(or) units Individual ponds, caves, wetlands, stream reaches, terrestrial quadrats, and so forth, that are occupied by an amphibian species. For most ARMI studies, sample sites are aggregated within the mid-level monitoring sites.

Species richness The number of amphibian species detected. This metric can be used to monitor spatial and temporal changes in targeted communities and can be applied to individual sites or the sample frame.

Stressor An environmental condition that alone or in combination with other conditions exceeds the range of an organism's tolerance and results in a decline in the viability of the organism and its population. 